\title{
Strategies For Improving Drought Resistance In Grain Legumes
}

\author{
G. V. Subbarao, C. Johansen, A. E. Slinkard, * R. C. Nageswara \\ Rao, N. P. Saxena, and Y. S. Chauhan \\ International Crops Research Institute for the Semi-Arid Tropics (ICRISAT), ICRISAT \\ Asia Center, Patancheru, 502 324, Andhra Pradesh, India
}

* A. E. Slinkard. Crop Development Centre. University of Saskatchewan. Saskatoon. Canada S7N OWO

\author{
Referee: Dr. R. J. Lawn, Division of Tropical Crops and Pastures, CSIRO, 306 Carmody Road, St. Lucia \\ Queensland 4067, Australia
}

\begin{abstract}
This review distills recent information on drought resistance characteristics of grain legumes with a view toward developing appropriate genetic enhancement strategies for water-limited environments. First. the possible adaptations that allow grain legumes to better cope with drought stress are summarized. It is suggested that there are considerable gains to be made in increasing yield and yield stability in environments characterized by terminal drought stress by further exploiting drought escape, hy shortening crop duration. Many traits conferring dehydration avoidance and dehydration tolerance are available, but integrated traits, expressing at a higher level of organization, are suggested to he more useful in crop improvement programs. Possible genetic improvement strategies are outlined, ranging from empirical selection for yield in droughted environments to a physiological genetic approach. It is suggested that in view of recent advances in understanding drought resistance mechanisms, the latter strategy is becoming more feasible. It is concluded that use of this recently derived knowledge in a systematic manner can lead to significant gains in yield and yield stability of the world's major grain legumes, as they are mainly grown (and will continue to be grown) under rain-fed conditions.
\end{abstract}

KEY WORDS: drought escape, dehydration avoidance, dehydration tolerance, root traits, osmotic adjustment. integrated traits, symbiotic nitrogen fixation, drought screening, physiological ideotype, breeding strategy.

\section{INTRODUCTION}

The advantages of including legumes in cropping systems have long been recognized (Nutman, 1987). The prime advantage is their ability to fix atmospheric nitrogen and thus positively contribute to the nitrogen $(\mathrm{N})$ balance of the cropping system. However, it must be recognized that such contributions may be of lesser significance for grain le- gumes than for forage legumes because of their high $\mathrm{N}$ harvest index (HI) and often poor nodulation (Hoshikawa, 1991). Other positive effects of legumes come from their ability to break disease cycles, improve soil physical conditions, encourage mycorrhizae, and mobilize normally unavailable soil phosphorus sources (Hoshikawa, 1991).

In developing countries at least, the everincreasing demand for cereal grain mitigates 
against the use of grain legumes in better endowed agricultural lands and often relegates them to less favorable, usually rainfed, environments (Saxena et al., 1993). Demand for grain legumes is increasing but economics of production still do not encourage their cultivation on the more productive soils (Saxena et al., 1993). Many of the biotic and abiotic stresses faced by grain legumes (Johansen et al., 1994) contribute to the large yield gap between potential yields and reatized yields as reflected in national production statistics (Table 1). Drought is the major abiotic stress in many parts of the world (Johansen et al., 1994). Constraint analysis can attribute large yield and production losses to moisture deficit, but hopefully these losses can to some extent be alleviated through appropriate research (Table 1). Improvements in grain legume productivity in drought environments should be considered not only in terms of increased grain yield, but also in improvements in soil physical, chemical, and biological factors as mentioned earlier. These improvements will further enhance the growth environment for non-legumes in the cropping system.

\section{TABLE 1 \\ Potentlal and Realized Grain Yields, Global Production Losses due to Drought, and Recoverable Yleld through Successful Drought Research Estimated for the ICRISAT Mandate Legumes}

\begin{tabular}{|c|c|c|c|}
\hline & Chickpea & Plgeonpea & Groundnut \\
\hline Potential yield ( $\left.t \mathrm{ha}^{-1}\right)$ & $6.5^{b}$ & $5.2^{c}$ & $9.6^{d}$ \\
\hline \multicolumn{4}{|l|}{ Regional mean yields $\left(t \mathrm{ha}^{-1}\right)^{\mathbf{e}}$} \\
\hline Asia & 0.71 & 0.74 & 1.17 \\
\hline Africa & 0.63 & 0.72 & 0.85 \\
\hline World & 0.72 & 0.75 & 1.15 \\
\hline \multicolumn{4}{|l|}{ Regional mean production ('000 t $)^{\ominus}$} \\
\hline Asia & 6.938 & 2,881 & 15,222 \\
\hline Atrica & 331 & 181 & 4,923 \\
\hline World & 7,700 & 3,153 & 23,336 \\
\hline $\begin{array}{l}\text { Global production }(t) \text { losses due to } \\
\text { drought ('000 t)' } \\
\text { Production recoverable from drought }\end{array}$ & 3,750 & 1,790 & 6,666 \\
\hline through crop improvement ('000 t $)^{\prime}$ & 2,120 & 1,090 & 667 \\
\hline
\end{tabular}

Dry grain yield for chickpea and pigeonpea and dry pod yield for groundnut. Winter-sown chickpea in Syria, 1983/1984 (Singh, 1987).

From three harvests of short-duration pigeonpea within $217 d$ in 1982/1983 (Chauhan et al., 1987).

Irrigated crop in Zimbabwe (Meterler Kamp, 1967).

Chickpea and groundnut data for 1991 from FAO (1992) and pigeonpea data for 1992 courtesy of E. A. Kueneman, FAO, Rome.

Calculated according to the procedure followed for the ICRISAT Medium Term Plan 1994 to 1998, based on 1991 global production data for chickpea and groundnut and 1992 data for pigeonpea. Losses estimated according to irrigation responses recorded in different regions and recoverable production estimated according to genetic advance in drought environments predicted by incorporating known sources of drought resistance and by exploiting drought escape. 
This review provides a status report on our understanding of drought response in grain legumes and summarizes current research on the enhancement of their growth and yielding ability in water-limited environments. We focus our attention on the grain legumes within our direct research experience, namely, chickpea (Cicer arietenum). lentil (Lens culinaris). pigeonpea (Cajanus (ajan), and groundnut (Arachis hypogaea). In addition. we also draw on relevant examples from the other grain legumes, mainly soybean (Glycine max), cowpea (Vigna unguiculata), black gram (V. mungo), and mungbean $(V$. radiara). Nevertheless, we refer to other crop plants to present our overall approach on various aspects related to drought resistance when relevant examples from legumes are not available.

It is recognized that genetic improvement is only one component of an integrated approach to stabilizing and improving crop production in drought environments. This review focuses mainly on the physiological mechanisms that influence the performance of grain legumes under moisture deficit. evaluating the scope for their genetic manipulation and discussing their relative importance in various production environments. Field screening methodologies and selection criteria based on yield and yield-derived in dices are discussed in the context of genetic improvement strategies. The problems associated with yield-based criteria and the philosophy behind a trait-based approach are discussed to establish a more analytical approach. We provide a conceptual framework for the integration of physiological mechanisms into genetic improvement programs for the development of drought-resistant grain legumes, based on a sound understanding of the biological defense mechanisms involved in adaptation to drought stress. We consider the strategies used previously to achieve progress in drought environments, propose improvements, and attempt to assess the potential impacts of current research endeavors.

\section{DEFINING TARGET DROUGHT ENVIRONMENTS}

For the purposes of this review, we define drought stress in the agronomic sense. viz. a reduction in grain yield attributable to plant water deficit. Grain legumes dependent on current rainfall are prone to intermittent drought stress during the vegetative or reproductive growth period: the crop's recovery from the drought is determined by subsequent rainfall. Terminal drought stress. which occurs during the pod-filling phase of crops, is common and a common yield reducer for crops growing with current rainfall (Nageswara Rao et al., 1985a,b) but is even more critical for crops grown during a postrainy season and reliant on stored soil moisture.

Thus, a first step in designing strategies to alleviate drought stress is characterization of the drought pattern of the target environment. This step has often been addressed inadequately in drought research programs, mainly because of the complexity of the task. However, this complexity has been reduced in recent years with the development of characterization tools such as soil water balance models (used as subroutines of crop growth models) and geographic information systenı (GIS) to assist in spatial visualization of the drought problem. Variability in soil moisture deficit must be considered over years for the entire cropping season. This knowledge permits estimation of long-term crop losses due to drought stress and the potential gains from alleviating drought stress through genetic and management options (Table 1).

\section{ADAPTATIONS TO COPE WITH MOISTURE DEFICITS}

Crop plants have evolved various mechanisms to cope with the drought stress patterns under which they naturally evolved or 
were domesticated. Thus, landraces are well adapted to local environmental conditions and have evolved a range of morphological, phenological, and physiological mechanisms to efficiently utilize the available production environment (White, 1988; Ashraf and Karim, 1991). This local adaptation becomes a dominant force and presents a major difficulty in evaluating drought resistance of a wide range of genetic material at any one location (White, 1988). Also, wild relatives may possess certain traits that may be relevant to drought resistance mechanisms of cultivated legumes (Parsons and Howe, 1984; Castonguay and Markhart, 1991). For instance, $V$. unguiculata ssp. unguiculata is well adapted to hot, semi-arid environments (Rachie and Roberts, 1974). This subspecies presumably originated in Africa and many landraces are found in the semi-arid and humid zones of West Africa (Steele, 1976). Also, subspecies in the wild, weedy. and alien gene pools, such as $V$. unguiculata ssp. dekindtianu, are native to the savanna of West Africa and Ethiopia, and can easily be crossed with cultivated cowpea (Rawal, 1975; Steele, 1976). Phaseolus acutifolius, a wild relative of $P$. vulgaris, has a higher osmotic adjustment ability than the cultivated bean (Parsons and Howe, 1984), which could he transferred to the cultivated bean through interspecific hybridization.

From an ecological perspective, survival and perpeluation of the genome plays a dominant role in the adaptation of a given landrace to a region. Consequently, these landraces usually have low yield potential, despite their superior local adaptation (Fischer and Maurer, 1978). Also, many of these landraces do not fit into present-day agriculture, where cropping systems and crop management practices are radically different from the conditions under which they evolved or were domesticated. Thus, it is important from the crop improvement perspective to identify the specific physiological attributes contributing to their adaptability to the moisture-defi- cit pattems of their native environment. This would assist breeders to selectively combine some of these physiological attributes into the high-yielding cultivars required for present-day production systems (Rosielle and Hamblin, 1981).

This section evaluates adaptations that grain legumes have developed during the course of their evolution or domestication, their relevance in different drought stress environments, and the scope for their favorable genetic manipulation. We follow Levitt's (1980) classification of traits relevant to coping with drought, with dehydration avoidance and tolerance considered as components of drought resistance. However, we also recognize that traits can be described at different levels of plant organization and thus discuss integrated traits.

\section{A. Drought Escape}

Drought escape is a particularly important strategy of matching phenological development with the period of soil moisture availability to minimize the impact of drought stress on crop production in environments where the growing season is short and terminal drought stress predominates (Turner, 1986a,b). As an example, local cultivars of cowpea flower progressively earlier along a transect from south to north through the Sudanian and Sahelian zones of Africa toward the Sahara desert (Hall et al., 1978). Flowering coincides with the average time of cessation of the rainy season (Bunting and Curtis, 1970), which is an adaptive characteristic. Plant breeding programs should, therefore, aim at developing high-yielding genotypes with phenological patterns to match probable seasonal soil moisture availability of a given environment (Fischer et al., 1982).

Landraces of chickpea, pigeonpea, and groundnut growing in their natural environments often face terminal drought stress, as 
evidenced by a yield increase if irrigation is given during the reproductive phase. This suggests that, despite their evolution and selection in specific environments, the duration to maturity of these landraces is 100 long in relation to the amount of stored soil moisture available (Singh and Subba Reddy. 1986). For instance, newly bred short-duration (early maturing) genotypes of groundnut are generally more successful compared with traditional long-duration genotypes in West African regions characterized by short growing seasons (Virmani and Singh, 1986). Several short-duration genotypes of legumes show higher and more stable yields than longer duration types (McBlain and Hume. 1980; Hall and Grantz, 1981: Hall and Patel, 1985: Rose et al., 1992). For most crop species, breeding for shorter duration is a major objective. not only to match phenology to season length, but also for other reasons such as to fit crops/genotypes into more intensive crop rotations.

For the ICRISAT mandate legumes, considerable progress has been made in shortening crop duration without unduly penalizing yield potential (Table 2). Similar progress has been reported in developing short-duration cowpea cultivars that escape terminal drought, but have yield potentials comparable with long-duration local cultivars (Hall and Patel, 1985). There is scope for more judicious matching of genotype duration with most probable soil moisture pattern using soil moisture balance models (Ritchie, 1985) in association with crop-weather modeling and GIS technology. A multilocation field testing program is costly and thus better preselection of genotypes to test, based on their fit to the probable soil moisture environment, should aid overall efficiency of the process. The more predictable the environment, the better the growth duration can be optimized.

However, various penalties are associated with reducing crop duration to better fit likely soil moisture patterns. Primarily, ear- liness ultimately reduces the potential yield of the crop by reducing dry matter at anthesis and the number of sites for postanthesis grain filling (Fischer, 1979). To some extent, this can be overcome by increasing the plant density. which is indeed a common practice where shorter duration genotypes are used. The degree of earliness required is generally a compromise between development of sufficient biomass without reducing soil water to a level that will limit reproductive growth (Fischer. 1979). Simulation studics in soybean have shown that early genotypes yield more than those maturing later if late drought reduces the yield of later maturing cultivars by at least 40\% (Muchow and Sinclair, 1986). It is sometimes observed that early maturing cultivars have shallow root systems (e.g., see Fereres et al., 1986; Arihara et al., 1991). This renders such cultivars more susceptible $t 0$ intermittent dry spells if grown as a rainy-season crop, in addition to a reduction in yield potential due to reduced water use (Fereres et al., 1986). However. genotypic differences in rooting depth have been reported in a number of legumes within a given duration, and thus this trait could be improved if necessary ( see Section III.B.I on root attributes). Also, the use of early maturity as an escape strategy is limited in some environments, such as for chickpea and lentil in Mediterranean environments, where too early flowering could expose the crop to low temperature and frost damage.

\section{B. Dehydration Avoidance}

Crop species have evolved several mechanisms to maintain plant water status within reasonable limits for normal metabolic functioning under limited water supply or when evaporative demand of the atmosphere become excessive. These can be broadly divided into two groups: maximizing water uptake through improving the ca- 


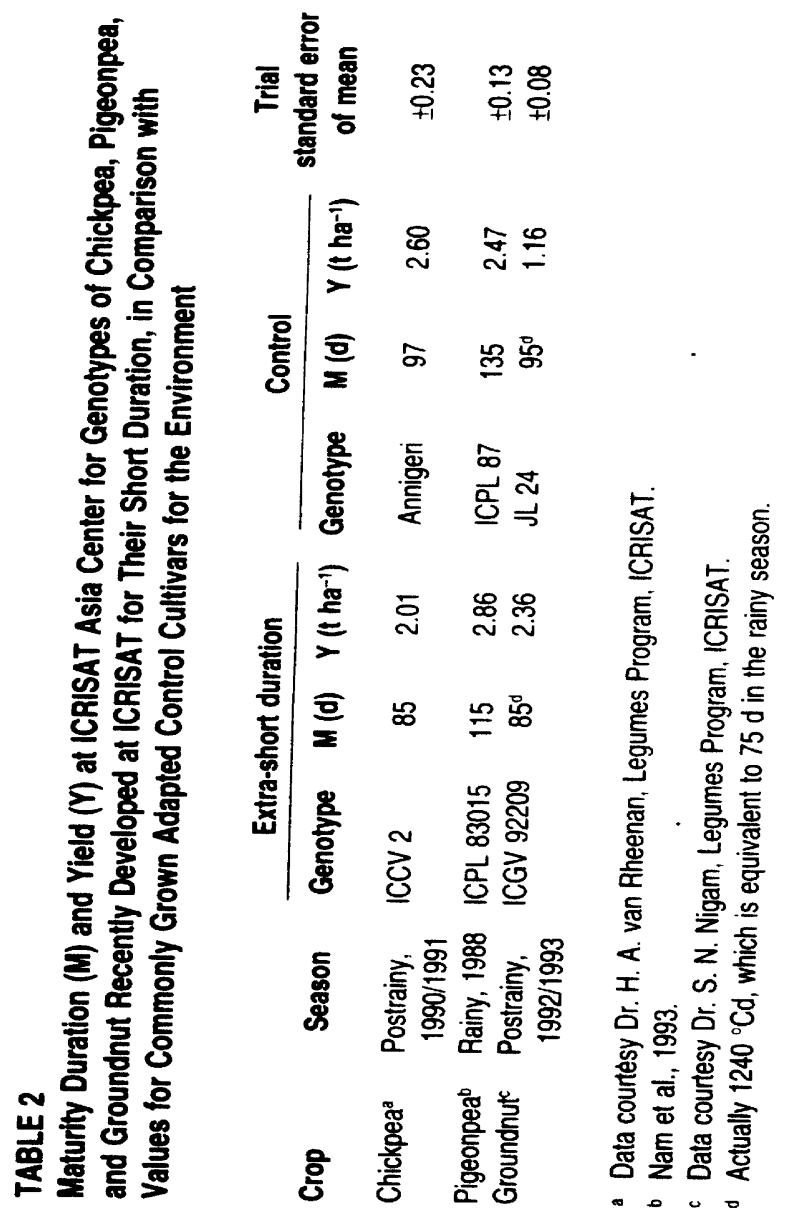


pacity of the root system to acquire water. and optimization of the use of absorbed water for the production of dry matter.

\section{Root Attributes}

Root size, morphology, depth. length. density, hydraulic conductance, and function are basic to meet the transpirational demands of the shoot (Passioura, 1982). For maximizing extraction of moisture from the soil the requirements are (1) deep penetration of roots; (2) adequate root density through the soil profile; and (3) adequate longitudinal conductance in main roots (Fischer et al., 1982). The water uptake pattern across the depth of rooting zone is not uniform. In general, nearly $40 \%$ of the total water uptake occurs over the first one fourth of the root zone, $30 \%$ over the second, $20 \%$ over the third, and $10 \%$ over the last fourth of the total rooting depth (Doorenbos and Pruitt, 1975; Nageswara Rao and Wright, 1994). Crop plants often maintain higher root length densities than are required in the surface layer: (1) to facilitate rapid uptake of recent rain before it evaporates: (2) to provide reserve capacity in case of disease or pest damage: (3) to extract relatively immobile nutrients like $P$; and (4) to compete with weeds or other neighboring plants for both water and nutrients (Passioura, 1983). Depending on the target environment, certain root traits may be more important than others and targeting of genetic improvement depends on the type of traits required relative to those present in current cultivars.

\section{a. Rooting Depth}

In the rain-fed environments, the depth of rooting and the ability to sustain an uninterrupted supply of water are important factors (Gregory, 1988). Even though terminal drought stress is common for many postrainy season legumes, crops are not necessarily limited by a deficiency of stored soil moisture. but by an inability of the crop either to fully extract water stored deep in the profile or extract it fast enough for yield formation (Jordan et al., 1983). Thus, inclusion of deeprooted lines in a breeding program for areas where substantial amounts of water are left in the subsoil at maturity seems justified (Gupta. 1992).

The growth of roots into deeper soil layers is a function of both genotype and environment; the interaction between the two often makes it difficult to distinguish genotypic differences in root growth (Gulman and Turner, 1978). Also, the growth duration of the genotype (long vs. short duration) affects root length, density, and rooting hehavior in general. For example, in pigeonpea. short-duration genotypes often extend roots only to about $50 \mathrm{~cm}$ depth compared with long-duration genotypes whose roots can extend to at least $2 \mathrm{~m}$ depth (Chauhan. 1993). Genotypic variation in rooting depth has been reported in several legumes (Kaspar et al.. 1984: White and Castillo, 1988).

Deep rooting was positively correlated with seed yield, crop growth, cooler canopy temperature, and soil water extraction in bean (Sponchiado et al., 1989). Drought-tolerant bean genotypes could extend their roots to $1.2 \mathrm{~m}$ depth in drought environments, whereas the sensitive genotypes could not extend their roots beyond $0.8 \mathrm{~m}$, and these differences in rooting depths were reflected in overall shoot growth and yield (White and Castillo, 1988). In groundnut, substantial genotypic variation in rooting depth, root volume, and water extraction pattern at different depths has been reported (Ketring. 1984; Mathews et al., 1988a; Wright et al., 1991; Chapman et al., 1993a). In soybean, differences in drought resistance were associated with rooting depth (Cortes and Sinclair, 1986). Wild relatives in many legumes possess deep rooting capability that could be 
transferred to cultivated legumes. A number of Phaseolus species, such as P. acutifolius, $P$. retensis, and $P$. coccineus, have deep and tuberous primary root attributes (Singh and White, 1988).

\section{b. Root Length Density}

Root length density ( $\mathrm{Lv}$, in $\mathrm{cm} \mathrm{cm}^{-3}$ ) usually decreases exponentially with depth (Wiebe, 1980). In many crops, Lv is more than sufficient to extract all available water in the surface layers (Passioura, 1983). However. at deeper layers, below $0.3 \mathrm{~m}$. Lv may not be sufficient to deplete available stril moisture. A plant that achieves $L v=0.5$ should be able to rapidly extract water without any difficulty (Passioura, 1983). Although roots in the surface soil may extract water below the lower limit of availability of 1.5 MPa, roots in the deeper soil often fail to extract water 10 this limit (Hurd, 1974; Jordan and Miller. 198()). Thus, it can be argued that if the plant could distribute its roots more uniformly throughout the root zone, it could better meet its water needs at various stages of growth without investing additional dry matter in roots.

In many grain legunes, Lv is lower $(0.13$ to $\left.0.70 \mathrm{~cm} \mathrm{~cm}{ }^{3}\right)$ than in cereals (around $2.4 \mathrm{~cm} \mathrm{~cm} \mathrm{')(Gregory,} \mathrm{1988).} \mathrm{Genotypic} \mathrm{dif-}$ ferences in Lv have been reported in many legumes, including faba bean (Looker. 1978). chickpea (Brown et al.. 1989), groundnut (Wright et al., 1994), pea (Bharadwaj et al.. 1971). cowpea (Babalola, 1980), and lentil (ICARDA. 1985). In many legumes. Lv continues to increase even after anthesis (Kaspar et al., 1978), which is in contrast to cereals where Lv stabilizes or declines after anthesis (Mengel and Barber, 1974). However, not all legume species continue active root growth during podfilling. Assimilate labeling studies and water extraction patterns suggest that root activity in soybean often declines during podfilling (Hume and Criswell, 1973). Nevertheless, in perennial legumes such as pigeonpea where a range of phenological plasticity (i.e., degree of indeterminateness) exists among varieties and genotypes, roots could be continuously active in genotypes that are more indeterminate in nature (Sheldrake and Narayanan, 1979). The differences between legumes and cereals in their root growth pattern offer at least partial complementarity in exploiting soil resources in intercropping systems (Reddy and Willey, 198I).

The type of root distribution required for a crop species depends on the target environment. In environments where the crop is grown on stored soil moisture, high Lv in the surface layers is not required. In this case. efforts should be directed toward increasing Lv at depth. On the other hand. if the crop is targeted for an environment where rainfall occurs in short spells during the growing season, then high $\mathrm{Lv}$ in the surface layers $(<0.5 \mathrm{~m}$ depth) is advantageous.

\section{c. Root Hydraulic Conductivity}

A decrease in root hydraulic conductivity could help in conserving soil moisture early in the season, so that it is available for grain filling (Passioura, 1972). The induction of a large hydraulic resistance within the plant (Passioura, 1983) should be beneficial in environments where grain yield depends on the amount of available water left in the soil at the onset of flowering (Passioura, 1972: Turk and Hall. 1980a,b). This should improve and stabilize yields where crops are raised with stored soil moisture by increasing the proportion of water used after the onset of flowering. By selecting for smaller metaxylem vessel diameters in the seminal roots, Richards and Passioura (1981a,b) developed wheat genotypes that could use water more slowly in early growth stages. How- 
ever, this screening method may not be applicable for legumes where secondary growth in the root increases the xylem tissue (Gupta. 1992).

\section{d. Scope for Genetic Improvement}

Deep rooting and increased root length density involve a substantial investment in carbon and maintenance costs. In sorghum. an increase of $\mathrm{Lv}$ from 1 to $2 \mathrm{~cm} \mathrm{~cm}^{-3}$. requires partitioning an additional $8(0) \mathrm{kg}$ $\mathrm{ha}^{-1}$ dry matter to the root system (Jordan and Miller, 1980). Passioura (1983) argued that the dry matter gain associated with the increased water supply will offset the dry matter investment into new roots. Simulation studies in sorghum indicated that yields of deeper rooted genotypes were at least $20 \%$ more than control genotypes in 1 out of every 3 to 5 years across locations (Jordan et al., 1983).

Screening and selection for rooting depth on a large scale is expensive and laborious (Blum, 1988). Thus, this type of evaluation is normally restricted to a few promising selected germplasm lines or cultivars and in choosing potential parents in a breeding program (Fischer et al., 1982). One method that permits evaluation of a reasonable number of germplasm lines was developed by Robertson et al. (1985). A selective herbicide is introduced at an appropriate depth and, as soon as the roots of an entry reach the herbicide, the plant develops toxicity symptoms. Thus, its use would be limited to the screening of lines or hybrids that are genetically reproducible. Identification of nondestructive herbicides would make it possible to apply this technique to evaluate segregating populations (Khalfaoui and Havard, 1993). This methodology is still being developed and requires standardization for any particular legume species before it can be used routinely for screening germplasm lines
(Hall and Patel. 1985: Khalfaoui and Havard, 1993). Root pulling resistance has heen suggested for characterizing root growth and has been used successfully in rice breeding programs at International Rice Research Institute (IRRI) (O'Toole and Soemartono, 1981: Ekanayaka et al.. 1985). Aeroponics gives a coarse estimate of potential rooting depth. but it also is a difficult technique. Tensiometers have been used to determine rooting depth (Fischer et al., 1982). Root effectiveness can also be quantified by measuring the apparent sap velocity (ASV), and cultivar variation in ASV has been reported in groundnut (Ketring, 1986).

Genotypic variation for root attributes has been reported for faba hean (Looker, 1978: ICARDA, 1984), chickpea (Nagarajarao et al., 1980; Brown et al., 1989), pea (Bharadwaj et al., 1971), lentil (ICARDA, 1985), groundnut (Nageswara Rao and Wright, 1994; Wright et al., 1994), and alfalfa (Medicago sativa) (Barnes, 1983). Despite adequate information on genetic variability, the use of root traits in crop improvement programs is only beginning. In chickpea, a drought-resistant genotype (ICC 4958) had $30 \%$ higher root dry weight than the standard control cultivar 'Annigeri', which is relatively more sensitive to drought stress (Saxena et al., 1994). Efforts are underway to combine this root trait with the adaptive and high-yielding traits of "Annigeri". Currently, a number of lines with ICC 4958 root phenotype and "Annigeri" shoot phenotype are being tested and some are showing promise of higher yielding ability in drought environments (Legumes Program, 1992). In durum wheat (Triticum durum), the deep and extensive root system attributes were combined with the agronomically superior but poor root system traits of cultivars such as Wascana and Wakooma, which led to the development of cultivars with root systems better adapted to drought conditions coupled with desirable agronomic 
attributes (Hurd et al., 1972, 1973). This demonstrates that root traits are amenable to genetic manipulation through normal breeding methods, provided suitable parents are ideniified and appropriate environments are used for expression of the trait.

It is important to evaluate the suitability of the screening systems for germplasm evaluation of root traits as the soil environment plays a major role in expression of root attributes. Genetic variability in root characteristics of sorghum grown in solution culture (Jordan et al.. 1979) is not expressed to the same degree in the field during drought (Jordan and Miller, 1980). A reordering of safflower (Carlhamus tinclorius) genotypes for Lv occurred when the growth medium changed from sand to clay (Harrigan and Barrs, 1984). These few examples imply that the suitability of the model system to the field situation must be demonstrated before large-scale evaluation of germplasm for root attributes is undertaken.

\section{Shoot Attributes}

A number of shoot attributes play inportant roles in regulating water use of crop plants when grown under moisture-limiting environments. These include developinent, structure, and surface properties of the canopy, ability to adjust the leaf area according to moisture availability, and functional attributes such as osmotic adjustment.

\section{a. Canopy Structure}

Canopy structure is determined by leaf size. leaf shape, leaf surface characteristics and reflectance properties, leaf angle, and the geometrical arrangement of leaves in the canopy. These traits determine the light extinction coefficient $(k)$ and radiation use efficiency (RUE) of the crop, and canopy structure plays an important role in controlling water loss from the canopy. Under field conditions, the boundary layer over crop canopies causes gas exchange to be less dependent on stomatal conductance, and thus can influence transpiration efficiency (TE) (Jarvis and McNaughton. 1986). Boundary layer resistance is a function of the thickness of the unstirred air boundary layer adjacent to the leaf, which depends on leaf size (Parkhurst and Loucks. 1972) and canopy architecture. The aerodynamic resistance of the canopy determines the relative importance of stomatal conductance to TE. If the canopy resistance to heat and water vapor diffusion is large, an increase in stomatal conductance (g) would tend to cool and humidify the air in the boundary layer, thus lowering the leaf-air vapor pressure deficit (vpd) and increasing TE (Farquhar et al., 1989: Read et al.. 1991).

With a closed canopy, solar radiation is attenuated downward with cumulative leaf area index ( $\mathrm{LAl})$ in accordance with Beer's law, with a $k$ characteristic of the canopy (Lawn. 1989). Crop cultivars with more erect and narrow leaves, and lower $k$ values, and hence higher critical leaf area index (CLAI leaf area index that intercepts $95 \%$ of the incoming solar radiation), generally have higher crop growth rates (Duncan. 1971). The advantage of narrow, vertically oriented leaves with a resultant higher CLAI and RUE has been well demonstrated in groundnut using mutants with variable leaf size and shape (Nageswara Rao, 1992). The narrow leaf mutant, TMV 2-NLM, has CLAl values around 5 to 6 compared with its parental line TMV 2, with CLAI values around 2 to 3 , although in both cases LAI reaches 5 at the onset of flowering. The RUE of the mutant is consistently higher than that of the parent (Nageswara Rao, 1992). Also, narrow leaves are considered to be an adaptive trait to stress conditions (Blum, 1980). In addition to this, because of aerodynamic implications, narrow leaves are usually stressed less (Gates, 1968). 
Many legumes produce leaf area beyond CLAI, which results in inefficient use of water and radiation for dry matter production and yield. For example. in groundnut. the $\mathrm{LAI}$ often reaches $>6$, although the CLAI is only about 2 to 3 (Williams et al.. 1986: Nageswara Rao. 1992). Leaf losses of up to $50 \%$ can be tolerated by many legumes, including pigeonpea and groundnut, without any major effect on yield (from our observations). For pigeonpea genotypes growing vegetatively during the rainy season. large vegetative growth was found to be less beneficial on a soil of low moisture storage capacity (Sheldrake and Narayanan. 1979). Thus, genotypes of legumes that are conservative in leaf area development beyond CLAI. and also have narrow leaves that permit better utilization of radiation and water. should be advantageous in water-limnited environments.

\section{b. Leaf Movements}

Once leaf area development is complutc an important mechanism by which legumes can adapt to drought stress is through changes in leaf angle (Begg, 1980)). Leaflets orient perpendicular to incident light in the absence of a water deficit but parallel to it during water deficits (Squire, 1990). This can effectively reduce the radiation load on water-stressed leaves when less water is available to dissipate the energy as latent heat, thus minimizing heat damage (Ludlow and Bjorkman, 1984: Forseth and Teramura. 1986). Advantages in ability to change leaf angle or orientation (paraheliotropism) are reversibility, rapidity of recovery on the relief of water deficit, and a minimum reduction in yield during water deficit (Shackel and Hall, 1979). The leaf orientation will allow maximum radiation interception when evaporative demand is low and WUE is high (Turner, 1982; Muchow, 1985b). Almost all legumes show a paraheliotropism response to radiation and water deficit. however, the degree of movement can vary among legumes or among genotypes of a given legume species (Lawn, 1982a: Ludlow and Bjorkman. 1984: Muchow, 1985b). Genotypic differences in paraheliotropism exist in some legumes. including groundnut (Lawn. 1982a: Ludlow and Bjorkman, 1984; Mathews el al., 1988b) and hean (Wien and Wallace. 1973: Sato and Gotoh, 1979). However, under severe moisture deficit environments, the contribution of parahcliotropism to genotypic performance would be limited (Mathews et al., 1988b).

\section{c. Leaf Surface Characteristics}

A smooth leaf is likely to lose more water than a crinkled leaf, which tends to create small pockets of still air (Rosenherg. 1978). The increased pubescence and waxiness observed under stress in some species, including legumes, increases leaf reflectance and reduces water loss (Ehleringer, 1980). Soybean lines with dense pubescence have higher TE (Baldochi et al., 1985). Leal pubescence may have an adaptive value in water-limited environments as the hairs allow the leaf to fix more carbon, to avoid potentially lethal high leaf temperatures, and lose less water daily, which allows the plant to extend its growth for a longer period into the drought (Ehleringer, 1980).

\section{d. Stomatal and Cuticular Characteristics}

By adjusting their apertures, stomata achieve the best compromise between the requirement for $\mathrm{CO}_{2}$ and the need to conserve water (Berninger and Hari, 1993). Stomata play a major role in regulating water loss so as to match the evapotranspirational demand to the water-supplying capacity of the roots, but this comes into operation when 
the fraction of transpirable water falls to 0.3 or below (Sinclair and Ludlow, 1986). This is essential in maintaining internal plant water status above a critical threshold level, thus contributing to dehydration avoidance strategies (Turner et al., 1984). Genetic variability for stomatal characteristics, such as stomatal density, aperture size, sensitivity to changes in internal and external water status, has been shown (Ciha and Brun, 1975; Tanzarella et al., 1984; Markhart. 1985). The heritability for stomatal characteristics is high, indicating the feasibility of genetically manipulating this trait (Jones, 1979: Buttery et al. 1993). The role of abscisic acid (ABA) in regulating stomatal function and improving TE has been highlighted recently (Mansficld and Davies, 1983; Hartung and Davies. 1991). Genetic variation in the capacity to accumulate ABA exists in many legume species (Eze et al.. 1983: Samet et al.. 1984). Inducible traits such as osmotic adjustment (see Section III.B.3 for further discussion) could lead to stomatal adjustment (partial opening) (Turner and Jones. 1980). Legumes that undergo little osmotic adjustment during water deficit. such as cowpea and siratro (Macroptilium atropur. pureum), effectively close their stomata to avoid dehydration (Shackel and Hall, 1983; Ludlow et al.. 1985: Muchow, 1985c). In contrast, crops such as pigeonpea and soybean, where osmotic adjustment occurs, permit stomatal adjustment until a critical internal water status is reached (Lawn, 1982a: Flower and Ludlow, 1986). Thus, differences in stomatal aperture reflect the inherent differences in metabolic strategies adopted by crop plants to regulate water loss. Therefore. stomatal size may not be directly amenable to genetic manipulation. rather it could be so indirectly through changing the efficiencies in metabolic strategies. Also, stomatal size in general is functionally related to TE; thus, it may be possible to select for optimum stomatal aperture size by selecting for higher TE (see Section III.D.4 for details).
Morphological features, such as a thick cuticle or wax deposits on the leaf surface. can reduce evaporational water losses from the leaf surface and thus minimize residual transpiration rate (Jefferson et al., 1989). Genotypes with lower residual transpiration rates usually have a functional advantage during moisture-limiting environments as this leads to efficient water use (Walker and Miller, 1986: Paje et al.. 1988). Genotypic variation in residual transpiration has been reported in soybean (Paje et al., 1988) and cowpea (Walker and Miller. 1986).

\section{Osmotic Adjustment}

Osmotic adjustment (OA) can be defined as the active accumulation of solutes within the plant tissue (either in roots or shoots) in response to a lowering of soil water potential (WP) (Morgan, 1984). This could lead to lowering of osmotic potential (OP), which provides the driving force for extracting water from iow WP. Osmotic adjustment can play a major role in determining the drought resistance of a given genotype by: (1) maintaining turgor over fluctuating soil water potentials, (2) maintaining stomatal conductance and thus photosynthesis, (3) maintaining growth, (4) increasing dehydration tolerance, and (5) increasing the extraction of soil water (Tumer and Jones, 1980; Wright et al.. 1983: Flower and Ludlow, 1986; Ludlow, 1987).

A wide variety of organic solutes accumulate in plant tissues during water and salt stress and contribute to OA (Gorham et al., 1985). The chemical nature of compatible solutes varies from one taxonomic group to another. but most are primarily organic constituents, particularly amino acids, organic acids. sugars, and derivatives of polyols or nitrogen dipoles (Meyer and Boyer, 1981). Also, inorganic ions accumulated from the soil can contribute significantly to the $\mathrm{OA}$; $\mathrm{K}^{+}$, and to a lesser extent $\mathrm{NO}_{3}^{-}$and $\mathrm{Cl}^{-}$, can 
accumulate to osmotically significant amounts (Morgan, 1992). The relative contribution of organic and inorganic solutes to OA varies among crop species. For example. in cotton, sorghum, and soybean, organic solutes play a major role in OA. whereas in sunflower, inorganic ions contribute a major share to OA (Jones, 1980). Reduction in solute potential (SP) can also occur through changes in the turgid weight/dry weight ratio (TW/DW), reducing the osmotic volume without accumulating additional solutes (Ludlow, 1980)a).

OA allows the plant to maintain gradients for water flow and to extract water from the soil at lower WP. while simultaneously maintaining turgor (Morgan, 1992). Also. $O A$ is associated with stimulation of root growth in pea (Greacen and Oh. 1972) and cereals. For example, wheat genotypes with low OA can not use water below a depth of $0.77 \mathrm{~m}$, whereas those with high OA extract water to a depth of $1.5 \mathrm{~m}$. indicating a greater rooting depth and more root growth due to OA (Morgan and Condon. 1986). Because OA allows more water to be extracted eithei by improving water extraction efficiency or improving the root growth by providing additional carbon (Morgan and Condon, 1986). it helps in maintaining stomatal conductance and photosynthesis (Boyer, 1976). OA permits stomatal adjustment and continued transpiration and photosynthesis under low water potentials in wheat and sorghum (Ludlow, 1980a). This may lead to continued fixation of carbon and thus plant growth over a longer period compared to genotypes that do not adjust osmotically (Ludlow. 1980a). However, in some cases, OA is not associated with improved root growth. If the additional water available to the crop by lowering the leaf $W P\left(W P_{1}\right)$ a few bars is not large enough to sustain transpiration for more than a few days, the impact on drought resistance will be limited (Jordan and Miller, 1980). Also, the impact of this additional carbon in determining yield depends on the growth stage at which the crop experiences the water deficit. If water deficit occurs during the heading or grain-filling stage. the additional carbon available due to OA may play a crucial role in preventing spikelet sterility, and in increasing grain set and seed-filling, thus improving $\mathrm{Hl}$ (Bingham, 1966; Morgan. 1980: Pierce and Raschke, 198()).

Osmotic adjustment is positively correlated with yield under drought environments in wheat (Morgan ct al., 1986), barley (Blum. 1989), and sorghum (Morgan, 1984). Increases in grain yield of as much as 50 to $60 \%$ have been attributed 10 OA in wheat (Morgan, 1983). In some cases, even a doubling in yield has been reported (Boyer. 1982). However, other reports indicate no relationship between $\mathrm{OA}$ and growth or yield under field conditions (Shackel and Hall, 1983: Munns, 1988; Blum et al., 1989). Also, in some cases. improved OA resulted in smaller cell size (Ackerson, 1981), and thus small organs and small plants. The smaller size of plant organs, as either source or sink, can result in lower potential yield (Blum, 1988). A negative correlation between OA and yield also has been reported (Grumet et al., 1987).

The increase in solutes that occurs with a reduction in $W P_{L}$ eventually reaches a limit, and this varies among crop species (Turner and Jones, 1980). The ecological habitat of the genetic materials, the growth stage, and growth conditions can influence the degree of OA (Morgan, 1983; Blum and Sullivan, 1986; Girma and Krieg, 1992). Significant genotypic variation has been reported in a number of legume crops (Table 3). Also, related wild species in legumes may possess high OA, but this has not been evaluated systematically. For example, the related species $P$. acutifolius had a higher range of OA compared with cultivated bean (Singh and White, 1988). More studies are required with germplasm lines and related species collected across wide geographical areas to examine the range of $\mathrm{OA}$ under moisture deficit. 


\section{TABLE 3}

\section{Values and Ranges of Osmotic Adjustment (OA) in Grain Legumes}

Legume species

\section{$O A$ in shoots}

Soybeans

Pigeonpea

Groundnut

Greengram

(V. radiata)

Black gram

(V. unguiculata)

Cowpea

(V. unguculata)

Lablab beans

(Lablab purpureus)

Lupin

\section{$O A$ in roots \\ Pea}

OA (MPa)

$$
\begin{aligned}
& -0.3 \text { to }-1 \\
& -0.12 \text { to }-1.28 \\
& -0.3 \text { to }-1.58
\end{aligned}
$$

-0.2 to 0.44

-0.05 to 0.5

0 to -0.40

$-0.2$

-0.14 to -0.48

-0.3 to -0.8
Ref.

Muchow, 1985c; Cortes and Sinclair, 1986, 1987;

Oosterhuis and Wullschleger, 1988

Muchow, 1985c; Flower, 1985; Flower and Ludlow, 1987; Lopez et al., 1987

Bennett et al., 1981, 1984; Erickson and Ketring. 1985; Black et al., 1985; Stirling et al., 1989; Ketring, 1986

Zhao et al., 1985; Muchow, $1985 \mathrm{c}$

Muchow, 1985c; Sinclair and Ludlow, 1986; Ashraf and Karim, 1991

Shackel and Hall, 1983; Muchow, 1985c; Sinclair and Ludlow, 1986; Lopez et al., 1987

Muchow, 1985c

Turner et al., 1987

Greacen and Oh, 1972

\section{Dehydration Tolerance}

The ability of cells to continue metabolizing at low $W P_{1}$ is termed dehydration tolerance. The last line of defense that a plant has against water deficit is a dehydration-tolerant protoplasm (Turner and Jones, 1980). Dehydration results in irreversible disruption of cellular organization and metabolism. although photosynthetic reactions can occur at severe water deficits in some lower plant forms (Santarius, 1967). Most crop plants belong to the dehydration-intolerant category; in general, plants with poorly developed drought-avoiding mechanisms have the greatest dehydration tolerance (Bewley. 1979). The relevance of dehydration tolerance in determining productivity under moisture-limited environments is debatable as, agriculturally, severe desicca- tion represents a small proportion of the total instances of drought (Boyer and McPherson, 1975). Furthermore, yield reduction duc to water deficit becomes important before severe desiccation occurs. However, enhancement of dehydration tolerance, which results in continued leaf growth and decreased senescence during mild or moderate drought. could have a positive effect on agricultural production. Sinclair and Ludlow (1986) considered critical relative water content as a most meaningful index for identifying legumes with contrasting differences in dehydration tolerance. In environments where water deficits can occur at any stage of growth, dehydration tolerance may have some role in survival of the crop until soil moisture levels improve with succeeding rains (Turner, 1979). 


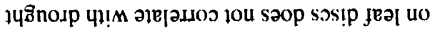

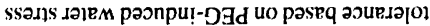

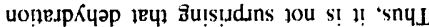

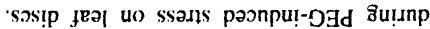

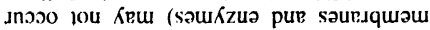

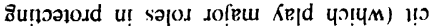

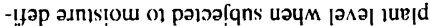

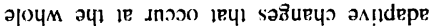

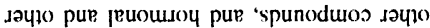

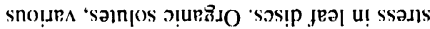

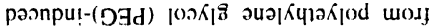

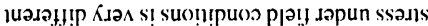

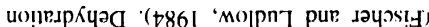
ndW 5ZI- Ol 59- sim I! sallunsolils

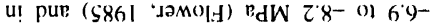

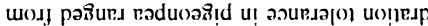

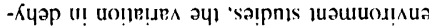

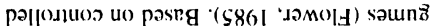
-

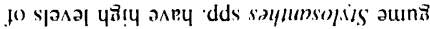

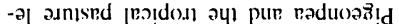

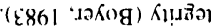

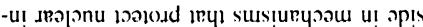
- ג Ки

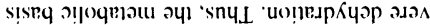

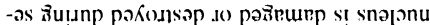

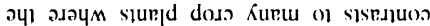
sıy ו :

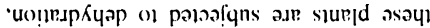

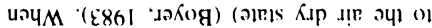

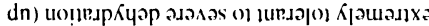

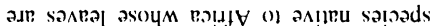

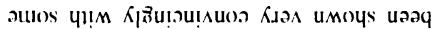

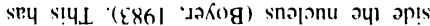
- Ino s.

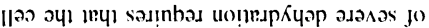

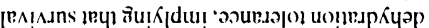

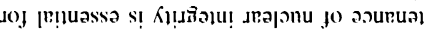
- -u!ew (986I ".

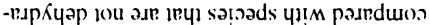

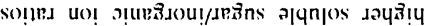

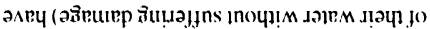
$\% 56$ ol dn 2sol uns s.j.

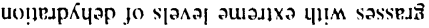
auos '(986I "Molpn pue faMold) $\forall O$

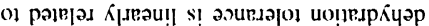

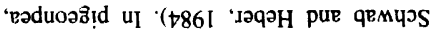

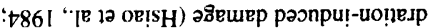

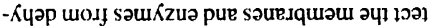
-odd әu!piəq pue әu! $\kappa_{[}[3 \mathrm{se}$ yons spunoduos un!uouure Kreusipnb pue "วu!fodd se yons sp!oe ou!ure 'sJeŝns se yons sainjos alq!!ed

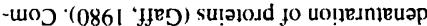

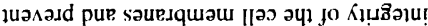

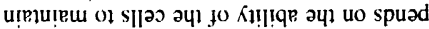

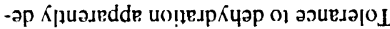

\section{จOUEJO/O।

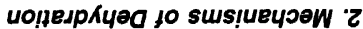

'

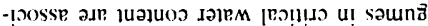

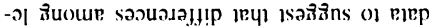

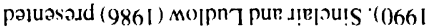

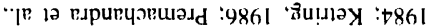

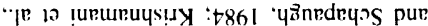

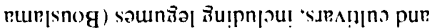

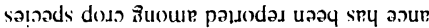

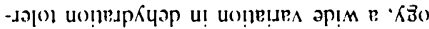

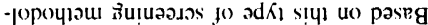

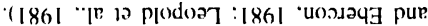

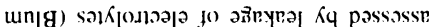
จq um әљ̋ d!aul dof padoss uayl pur ssads inay pup

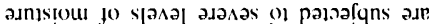

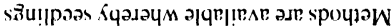

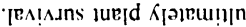

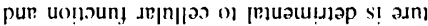

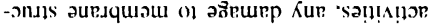

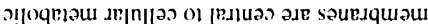

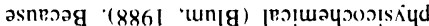

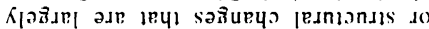

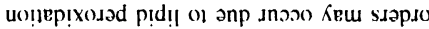

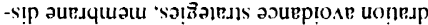

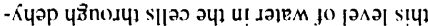

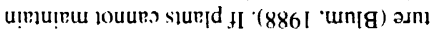

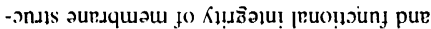

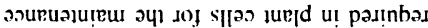
s! dolen fo $\% 0 \varepsilon$ ol 82 fo wnu!

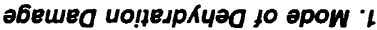


resistance based on either field or controlled environment evaluation of plants (Hall et al.. 1984).

Little information is available regarding genotypic variability for dehydration tolerance in legumes. Also, as dehydration tolerance is a survival trait, the expression of this trait and its contribution to drought resistance of a given crop species depends on the level of stress that the crop experiences during the growing season. Furthermore, its usefulness can be realized only if it is placed in a genetic background that has other mechanisms related to maintenance of production under moisture-deficit environments. High dehydration tolerance is usually associated with slow rates of growth and development, and most plants with good dehydration tolerance lack dehydration-avoidance strategies (Ludlow. 1980b). Mechanisms that allow plants to avoid dehydration could override the benefits of dehydration tolcrance, thus making it difficult to quantify the contribution of this trait to drought resistance.

Nevertheless, it is considered that moderate dehydration tolerance is desirable in crops of semi-arid environments (Steponkus et al., 1982). Dehydration tolerance coupled with stomatal adjustment contributes to greater drought resistance of sorghum in semi-arid areas (Ludlow. 1980) hydration tolerance is not energy consuming (Boyer, 1992), is stable from generation to generation. and is related to field performance during drought, at least in some cases (Wright and Jordan. 1970; O`Toole et al.. 1978).

\section{Integrated Traits Assisting Crop Performance}

Integrated traits, such as seedling establishment, early growth vigor, and leaf area maintenance, are determined by a number of functionally integrated mechanisms that may contribute to both dehydration avoidance and tolerance aspects. Such traits are easier to quantify in a breeding program where many lines must be evaluated.

\section{Seedling Establishment}

In arid and semi-arid environments, soil moisture in the seed-bed can be suboptimum. which causes reduced germination and emergence, and results in low yields (Saxena. 1987). Even for postrainy season crops that are raised on stored soil moisture. germination and seedling establishment may be affected by suboptimal surface soil moisture level at sowing. In south Asia. high temperatures and evaporative demand between the end of the monsoon rains and the time of sowing result in a rapid loss of soil moisture in the surface layers. Consequently, moisture at seeding depth is often insufficient for germination. emergence. and establishment. Poor and irregular plant stands are a major cause for the large yield gap between farmers" fields and experiment stations, for chickpea at least (Saxena. 1987).

Rapid root development and growth wopld facilitate successful establishment of seedlings when soil moisture is suboptimal after sowing (Asay and Johnson. 1983). Successful establishment of seedlings during periodic dry spells requires a primary root capable of rapid downward elongation because of frequent and severe drying of the seed-bed. which may restrict development of lateral roots (Jordan and Miller, 1980). Also, the lateral roots may be required to grow through relatively dry layers of soil to reach moist regions deeper in the profile. Because mechanical resistance to root growth increases dramatically as soil moisture level decreases (Taylor and Carson, 1974), these roots must be capable of exerting considerable growth pressure, possibly through alterations in root diameter or OA in roots (Hsiao 
et al., 1976). For crops planted at the beginning of a rainy season, the capacity to quickly develop a deep root system may not be required initially, as only the surface soil would be wetted initially. However, vigorous root development and growth are apparently important for seedling survival under conditions where the soil surface dries rapidly. but sufficient soil moisture is available in deeper zones. This is probably one of the reasons for the finding that vigorous seedlings survive better than those less vigorous (Blum et al., 1977). Also, dehydration tolerance of the leaf tissue and meristems may play an important role in protecting the seedling, and thus maintaining the plant stand.

Genotypic variation in the ability to germinate and establish seedlings under suboptimal moisture levels has been reported in legumes (Wright. 1971: Bouslama and Schapaugh. 1984: Kang et al. 1985: Saxena. 1987: Seong et al., 1988: Soja et al.. 1988). Generally, crops require a critical seed moisture level to germinate and this varies among crop species. For example. for chickpea, a $20 \%$ soil moisture level is critical in a Vertisol (32\% soil moisture is close to field capacity in this Vertisol), below which none of the tested genotypes could germinate (Saxena, 1987). Genotypic differences werc reported in chickpea for emergence at the 21 to $22 \%$ soil moisture level; several genotypes, such as G-130. Rabat, and Annigeri, were considered tolerant compared with genotypes L-550) and K-4-1 (Saxena, 1987).

\section{Early Growth Vigor}

Early development of the crop canopy is necessary to optimally utilize the production environment (i.e., light, water, and conducive temperatures). This is particularly so for short-duration varieties in order to match the crop duration to the length of the growing season. In Mediterranean environments, early vigor would lead to improvement in WUE because water use early in the season. when vapor pressure deficits (VPD) are smaller. would improve TE, compared with water use at the end of the season when increasing temperatures and higher VPD reduce TE. Rapid early growth and canopy development will reduce surface soil evaporation, thus increasing the moisture available for transpiration. However. if the crop is raised entirely on stored soil moisture, then early growth vigor needs to be balanced with rate of moisture use to ensure that enough moisture is left for the grain-filling period. Simulation modeling could assist in estimating the degree of growth vigor required for a given production enviromment. taking into account the stored soil water supply (which is influenced by soil type and depth) and demand (which is influenced by VPD and LAI). Genetic variation has been reported in early vigor in several grain legumes (Onim, 1983; Silim et al., 1993), indicating the feasibility of manipulating this trait as required for specific environments.

\section{Leaf Area Maintenance}

Leaf area expansion is more sensitive to drought than photosynthesis and transpiration (Turner and Begg, 1977: Muchow, 1985b; Hoogenboom et al., 1987). Significant genotypic differences in leaf area expansion have been reported in legumes such as soybean (Muchow, 1985b). When moisture deficit develops slowly, crops tend to adjust their transpiring surface area through reducing leaf growth and enhancing senescence of older leaves to balance transpirational demand against reduced water uptake (Hsiao, 1982). This is a mechanism for reducing water loss as, below an LAI of about 3 , crop transpiration is reduced linearly with leaf area under dry soil surface conditions (Ritchie, 1985). This occurs for production 
environments relying on stored soil moisture. In many cases, development, maintenance, and adjustment of optimum leaf area is the main yield-determining factor in these environments (Fischer and Turner, 1978).

However, under rain-fed conditions where intermittent drought patterns are common, the ability to retain leaf area during the period of moisture deficit plays an important role in determining productivity of the genotype. Some legumes have a tendency to shed a large proportion of leaf area when subjected to moisture deficit after the canopy is fully developed (Constable and Hearn, 1978; Muchow, 1985b). Although, pigeonpea falls into this category, the ability of short-duration pigeonpea to retain leaf area is positively related to yield when plants are exposed to drought stress at the vegetative or flowering stage (F.B. Lopez et al. ICRISAT, unpublished data). In groundnut, large genotypic differences in leaf area reduction have been ohserved under drought conditions (Nageswara Rao and Wright. 1994).

The ability to retain leaf area is an integrative function of many lower-level traits such as a deep root system, other root traits related to moisture extraction. stomatal control. OA. dehydration tolerance, and leat movements. In many cases, leaf fall occurs as the plant fails to maintain $W_{1}$ above a critical level, leading to either death or abscission of leaves. Thus, it seems that genetic improvement of crop performance under drought conditions may be based on genotypes that retain leaf area during drought but undergo the usual senescence at maturity (Boyer, 1983). This leaf retention trait is easy to visually assess among large numbers of test lines, as in a breeding program.

\section{Transpiration Efficiency}

TE is defined as aerial dry matter produced per unit of water transpired by the crop. Accurate estimates of TE for different genotypes of a crop for the entire growing season (season-long TE) are difficult and laborious to obtain (Tanner and Sinclair, 1983). Because of this practical difficulty in evaluating TE. not much progress has been made in the past in the genetic improvement of TE in any crop species, although genotypic differences in TE were reported as early as 1913 (Briggs and Shantz. 1913). Photosynthetic rate (A), transpiration rate $(T)$, and $\mathrm{TE}(\mathrm{A} / \mathrm{T})$ can be reliably and accurately measured by gas-exchange procedures. However, these measurements are instantaneous and do not represent integrated TE during the plant growth. The recent finding that TE is negatively correlated to carbon isotope ( ${ }^{13} \mathrm{C}$ ) discrimination $(\Delta)$ in $C_{3}$ plants (Farquhar and Richards, 1984) has led to a renewed research interest in TE as a trait exploitable by plant-breeding programs.

Carbon isotope discrimination can be used to quantify internal $\mathrm{CO}_{2}\left(\mathrm{C}_{1}\right)$ levels of leaves on a long-term basis (Farquhar et al.. 1982, 1989: Subbarao et al., 1994). Carbon isotope discrimination and TE are related to each other through independent relationships with the ratio of internal $\mathrm{CO}_{2}$ pressure to ambient $\mathrm{CO}_{2}$ pressure $\left(\mathrm{P}_{1} / \mathrm{P}_{\mathrm{a}}\right.$ ) (Farquhar et al. 1982). This depends on the way in which plants coordinate leaf conductance and assimilation of $\mathrm{CO}_{2}$ at a constant leaf-to-air vpd. Variation in coordination of leaf conductance and assimilation rate can give rise to variation in $P_{1} / P_{a}$, thus in $\Delta$ and TE (Hubick et al., 1988). Based on the theory, higher TE is negatively correlated with $\Delta$ (Farquhar et al. 1989). This relationship between $\Delta$ and TE in plants with a $C_{3}$ photosynthetic pathway has been confirmed for several crops (Winter, 1981; Farquhar and Richards, 1984; Hubick et al., 1988: Wright et al., 1994). However, if plant breeding is to effect detectable changes in TE of dry matter production. then $\left(1-P_{i} / P_{a}\right)$ needs to be modified substantially (Tanner and Sinclair, 1983). 
Several attempts have been made in cereal and legume crops to assess and establish genotypic variation in TE using $\Delta$ as a tool. Genotypic variation in $\Delta$ has been reported in sunflower (Virgona et al.. 1990). groundnut (Hubick et al.. 1986: Wright et al.. 1994). cowpea (Hall et al., 1990. 1992), hean (White et al.. 1990), and wheat (Farquhar and Richards. 1984: Read et al.. 1991). An increase of $1 \%$ in $\Delta$ corresponds to a decline of $23 \%$ in TE of Altai wild rye (E/ymus dahur sp.). $26 \%$ in crested wheatgrass (Agropyron desertorum) (Johnson et al.. 1990 ). $19 \%$ in wheat (Farquhar and Richards, 1984 ) and $17 \%$ in groundnut (Hubick et al.. 1986). The variation in TE among several crops has been quantified, viz. $59 \%$ in wheat (Farquhar and Richards, 1984). 65\% in groundnut (Hubick et al., 1986). and $67 \%$ in cowpea (Kirchhoff et al. 1989).

Despite considerable genetic and environmental (nutrition. light intensity, water status) effects on the individual components of $\mathrm{A}$ and $\mathrm{g}$ (stomatal conductance) separately. Farquhar et al. (1987) suggested that variation in the ratio of $\mathrm{A} / \mathrm{g}$, hence $\mathrm{P}_{\mathrm{i}} / \mathrm{P}_{\mathrm{i}}$. and $\Delta$ is likely to be small because of coordination between $A$ and $g$. This is reflected in coefficients of variation for $\Delta$ typically $<4.5 \%$ (Johnson et al., 1990), making selection for $\Delta$ highly attractive to plant breeders. This coordination between $\mathrm{A}$ and $\mathrm{g}$ could lead to predictable genotypic differences in $\mathrm{P}_{1} / \mathrm{P}_{\mathrm{a}}$ and $\Delta$ (Hubick et al., 1988).

In groundnut, genotype $\times$ environment $(G \times E)$ interaction for $\Delta$ is not significant. suggesting that $\Delta$ is primarily under genetic control (Nageswara Rao and Wright. 1994). Genotypic ranking was maintained at different sites and between wheat genotypes grown in pots and in the field (Condon et al., 1987). The broad sense heritabilities for $\Delta$ ranged between 60 and $90 \%$ for wheat (Ehdaie et al. 1991) and for groundnut (Hubick et al., 1988). In groundnut and cowpea, heritabilities for $\Delta$ were similar under dry and wet conditions (Hubick et al., 1988: Hall et al., 199()). Similar findings were reported for other crops such as wheat (Ehdaie et al., 1991) and sunflower (Virgona et al., 199()).

\section{Developmental Plasticity}

Developmental plasticity can be defined as the ability to adjust the duration of different growth phases to suit moisture availability during the growing season. This includes the ability of a plant to recover from a period of drought stress. Incorporation of a wider range of developmental plasticity into crops grown under moisture-limiting environments is an important strategy to consider in developing cultivars with stable performance in drought prone areas (Mungomery et al.. 1974: Saced and Francis, 1983; Weaver et al., 198.3). For instance, landraces of bean grown in endemic drought areas of the Mexican highlands possess a high degree of developmental plasticity, thus giving assured but low yiclds under drought conditions (Singh and White, 1988). Cowpea is more drought tolerant than soybean mainly duc to its greater developmental plasticity (Lawn, 1982b,c). However, developmental plasticity is primarily a conservative trait, and there is normally an inevitable trade-off with yield potential under optimum environments.

Developmental plasticity includes an ability to adjust canopy development pattern according to soil moisture availability. This would involve leaf area adjustment, leaf movements, stomatal control, and ability to produce new leaves on relief of moisture deficit. Developmental plasticity also depends on plasticity of the root system. Flexibility of reproductive development patterns is also required, with ability to adjust maturity according to soil moisture availability, and ability to produce new flushes of flowers and pods when the moisture situation improves (e.g., as in pigeonpea [Chauhan et 
al., 1987]). Some genotypes of chickpea can initiate pod set and filling at lower nodes at an early growth stage to ensure filling of at least some pods in a receding soil moisture situation (Saxena et al., 1993). In groundnut, peg initiation and elongation ceases when soil moil moisture is depleted to $80 \%$ of the extractable limit (Chapman, 1989). However, those pegs initiated prior to or during the drought period had the capacity for renewed elongation after rewatering. This plasticity in pod development apparently plays an important role in the adaptation of groundnut to intermittent drought situations (Harris et al.. 1988).

Phenological plasticity is a function of degree of sensitivity to photothermal time. Flowering in legumes is generally sensitive to variation in both temperature and photoperiod (Sumnerfield and Wien, 1980); Bell and Harch, 1991). Response to photothermal conditions is a major component of $\mathrm{G} \times \mathrm{E}$ interactions (Summerfield et al., 1985). In hean drought adaptation trials, cultivars possessing day neutral response proved advantageous at higher latitudes, whereas photoperiod-sensitive materials were hetter suited at low latitudes (White. 1988). Phenological plasticity determines the optimum reproductive growth duration, rate of pod filling, and the pattern of pod development and thus could play an important role in determining the adaptation of a genotype to a given target production environment.

Genotypes with reproductive development spread over an extended period, and which can be delayed by drought, are more suited to environments with bimodal rainfall distribution or where drought can occur at any time. Genotypes with reproductive development compressed or delayed little by drought would be more successful when grown on early concentrated rainfall or under stored and receding moisture conditions (Harris et al., 1988). Thus, the degree of phenological plasticity required in a given cultivar depends on the production environment. Indeterminacy, plasticity in branching, potentially long growth duration (e.g., perenniality), phenological plasticity (i.e., ontogenic flexibility) (Lawn, 1982c: Muchow, 1985a), profligate production of sink capacity (Ojehmon, 1970), and ability to produce sequential flushes of flowering and podding provide scope for developmental plasticity in many legumes and play major roles in adaptation to marginal environments (Minguez et al.. 1993). In pigeonpea, the flowering and early podding stage is particularly susceptible to soil moisture deficit (F.B. Lopez et al. ICRISAT. unpublished data). Thus, indeterminate types for determinate types with less synchronous flowering) would permit greater chance of pod set under intermittent drought conditions. Furthermore, indeterminate plant types are better able to produce new leaves on relief of drought stress, and thus continue the vegetative phase to produce more biomass. However, determinate pigeonpea also shows genotypic variability in ability to regrow, or ratoon. after harvest or damage to an earlier flush (Johansen et al., 1991). Determinate and indeterminate types have both mirual advantages and disadvantages depending on the target cropping system and production environment.

Generally, higher levels of developmental plasticity have contributed to vegetatively vigorous but poor-yielding phenotypes and contribute to a lack of adaptation to inputs of fertilizer and irrigation. mechanical harvesting. and other management inputs. Soybean has been considerably modified by man to better adapt to higher levels of management and thus shows less plasticity than legumes such as pigeonpea, groundnut, chickpea, cowpea, and mungbean. However, significant genetic variation can be found within many legume crops in various components of developmental plasticity. Genotypic variation in rooting pattern has been reported for 
several crop species, including the adjustment of rooting depth and root length distribution pattern to changing moisture availability (Carter et al., 1982). Similarly, for other components such as canopy structure and rate of phenological development. genotypic variation has been reported (Fischer and Turner, 1978). Plant breeders have been quite successful in incorporating various degrees of phenological plasticity (i.e., degree of indeterminacy) in many legumes. including pigeonpea. chickpea, and groundnut (ICRISAT, 1990, 1991). This has led to the development of cultivars that can best fit particular production environments (Hall et al.. 1978: Turner, 1979).

\section{Mobilization of Preanthesis Stored Reserves}

Remobilization of starch reserves stored in stems contributes significantly to grain yield of legumes (Constable and Hearn. 1978). These carbohydrate reserves act as a buffer against availability of current photosynthates, particularly during grain filling (Schnyder, 1993). Because translocation is more tolerant than photosynthesis and respiration to moisture deficit (Boyer, 1976), the ability to store and mobilize large quantities of carbohydrates for OA, or for grain filling under terminal drought, should improve the ability of a cultivar to perform under drought conditions (Bidinger et al., 1977; Blum et al., 1983a,b). Also, ABA has a major role in inducing mobilization after anthesis (Teitz et al., 1981), as at this stage grain growth enters its exponential phase (Blum et al., 1983a,b). A significant positive relationship exists between the rate of stem dry matter loss after anthesis and grain production capacity under conditions of moisture deficit across a range of genetic materials (Rawson et al., 1977). Also, this could play a crucial role in determining the sink strength by pre- venting mega-gamete sterility, thus protecting reproductive development. if stress occurs at the flowering stage (Boyer, 1992).

Grain growth in legumes is partially supported by translocated plant reserves (Meckel et al.. 1984; Westgate et al., 1989; Wright et al., 1991). These reserves are mainly nonstructural carbohydrates, which can be mobilized for various plant needs under moisture deficit. which is particularly necessary if current assimilation cannot meet plant requirements (Ludlow and Muchow, 199()). The relative contribution of these reserves to total grain yield is. however, dependent on the growth duration of the cultivar. crop species. and the environmental conditions during pod filling. In crops such as faba bean, nearly $45 \%$ of the total stem weight comprises remohilizable starch reserves, compared with only $18 \%$ in soybean (Hanway and Weber, 1971). Nearly $90 \%$ of the seed nitrogen and $42 \%$ of the seed dry matter in munghean came from remobilization of reserves stored during preanthesis (Bushby and Lawn, 1992). In soybean, 25\% of the grain weight was produced from stem reserves under rain-fed conditions (Constable and Hearn, 1978).

Remobilization of stored reserves can influence the performance of a genotype in both intermittent and terminal moisture-deficit environments. In intermittent moisturedeficit situations, stored carbohydrates determine the ability of a genotype to recover from stress (Sheldrake and Narayanan, 1979). Under conditions of terminal moisture deficit, net photosynthesis decreases (Berry, 1975), thus the proportion of translocation of stored soluble carbohydrates for grain filling becomes larger, although it is essentially the same in absolute terms (Austin et al., 1977; Bidinger et al., 1977; Fischer, 1979). In chickpea, nearly 15 to $20 \%$ of the total grain weight is derived from remobilization of stored carbohydrates (Saxena, 1984; Singh, 1991). For legumes, which are inde- 
terminate in nature, the question of reserves contributing to grain yield is complicated by the long time interval over which flowering extends. Nevertheless, it is possible that reserves that accumulate before the onset of flowering can buffer yield against stress during seed filling, as has been suggested for dryland soybean (Constable and Hearn, 1978; Westgate et al., 1989), munghean (Bushby and Lawn, 1992), and chickpea (Saxena, 1984: Singh, 1991). Thus, for dry Mediterranean environments, Richards and Thurling (1978) suggested selection for greater growth before anthesis, when water is unlikely to be limiting, hence placing greater emphasis on seed filling reliant on mobilizable reserves formed during early growth.

Methods are now available to quantify the contribution of stored preanthesis reserves for grain yield under terminal drought environments. This involves removing the green leaf area by spraying chemicals such as magnesium or sodium chlorate $(4 \%$ active ingredient) $14 \mathrm{~d}$ after flowering, thus forcing plants to rely entirely on stem reserves for grain filling (Blum et al., 1983a,b). This has been attempted in cereals, including wheat. harley, sorghum, and millets (Panicum and Pennisetum spp.) (Blum et al., 198.3a,b). In several crops, including groundnut, genotypic variation has been reported in the ability to store and mobilize carbohydrates for seed filling during terminal moisture stress (Chapman, 1989; Wright et al., 1991). Several tall landraces of wheat and harley possess substantial ability to store and remobilize carbohydrates for grain filling compared with modern wheat and barley cultivars (Blum et al.. 1989). Similar variation has been reported in mungbean, which suggests the possibility of genetically manipulating this trait (Bushby and Lawn. 1992).

Although build-up of higher levels of nonstructural carbohydrate reserves during the preflowering stage is advantageous in stabilizing grain yield across environments with fluctuating soil moisture levels, this trait also may have a number of negative effects. First, constitutive adaptation of accumulating large reserves before anthesis to guarantee seed filling involves a penalty to yield potential under optimal conditions. Also. during the early reproductive stage. reproductive sinks will have to compete with the reserve mobilization, which could lead to sink limitation. If the crop faces optimum moisture levels at the seed-filling stage, this would mean yield would be limited by sink size.. and also the reserves that were built up would remain unutilized. Second, rapid mobilization of large quantities of preanthesis carbohydrates during seed filling would also enhance the danger of predisposing the stem to fungal infections or lodging could occur due to weakening of the stem. This has been shown in sorghum. in which genotypes that mobilize large quantities of carbohydrates stored in the stem during seed filling were more sensitive to charcoal rot (Macrophomina phaseolina) under conditions of terminal drought stress (Rosenow et al.. 198.3).

\section{Symbiotic Nitrogen Fixation}

The interaction between drought stress and symbiotic nitrogen fixation in grain legumes must be understood. not only to establish how best to meet the nitrogen needs of the legume itself, but also to optimize addition of fixed nitrogen to the cropping system in drought-prone environments. Symbiotic nitrogen fixation is particularly sensitive to environmental stresses: conditions that may not be stressful for either of the partners alone could be suboptimal for the symbiosis (Chapman and Muchow, 1985; Sinclair. 1986). The delicate balance between the host plant and the symbiont demands an optimum soil moisture environment for maximum efficiency of $\mathrm{N}_{2}$ fixation (Swaraj, 1987). 
Most tropical and temperate legumes require soil moisture levels of at least 70 to $80 \%$ of field capacity for optimum function of the legume-Rhizobium symbiosis (Johnson et al., 1981: Swaraj. 1987).

Because of the high sensitivity of the legume-Rhizobium symbiosis to water deficit. nitrogen availability is often a limiting factor for growth and productivity of many legumes under moisture-limiting environments (Sinclair et al.. 1988: Sall and Sinclair, 1991: Kuhad et al., 1992). Many field and controlled environment studies on tropical and temperate legumes have reported an adverse effect of moisture deficit on the legume-Rhizohium symbiosis (e.g.. see Engin and Sprent. 1973; Chapman and Muchow. 1985: Sinclair et al.. 1988: Davies et al. 1989: Djekoun and Planchon, 1991). The degree of sensitivity may vary among grain legume species (Smith et al., 1988) or even among genotypes of a given grain legume (Williams and Sicardi-de-Mallorca. 1984: Sall and Sinclair. 1991).

The legume-Rhizobium symbiosis involves a complex interaction between the host root. the rhizobial strain, and the environment. Moisture deficit may affect any phase of the legume-Rhizobium symbiosis. viz. Rhizobium survival and growth in bulk soil or the rhizosphere, rhizobial infection of the host root tissue, initiation, development, and function of the nodule and growth of the host legume. including its ability to maintain a supply of photosynthates, nutrients, and water to the root nodules.

\section{a. Rhizobial Infection and Nodule Initiation}

Rhizobial survival, multiplication, and migration in the rhizosphere of the host root is important for the successful establishment of symbiosis. Rhizobia can survive in soils of low water potential, are quite resistant to soil drying, and can survive in water films surrounding soil particles (Williams and Sicardi-de-Mallorca. 1984). Rhizobium strains differ in their ability to survive under moisture-deficit conditions. In general, the fast-growing rhizobial strains are more sensitive to soil dehydration than slow-growing strains (Sprent, 1971). However, most rhizobial strains can survive at moisture levels much below those critical for plant growth. Thus, rhizobial survival may not be a limiting factor for the successful establishment of symbiosis under moisture-deficit conditions (Worrall and Roughley, 1976; Swaraj, 1987). However, low soil moisture content slows or prevents movement of rhizobia to the root surface (Handi, 1970), as the water-filled pores in the soil become discontinuous, thus contributing to poor nodulation in legumes growing in soils with water levels below field capacity at early growth stages.

The rhizobial infection process is more sensitive to moisture deficit than rhizobial survival and multiplication in the rhizosphere. In many cases, plants fail to nodulate under moisture deficit, even with sufficient rhizobia in the rhizosphere (Worrall and Roughley, 1976). Moisture deficit may result in greater adhesion between root hairs and soil particles (Sprent, 1975), thus affecting the physical relationship between bacteria and root bairs. Production of extracellular material by one or both partners may affect the establishment of a symbiotic system under moisture deficit. Also, distinct wetting and drying cycles, common in semi-arid environments, enhance nitrification and can produce soil nitrate levels sufficiently high to inhibit nodulation (Brockwell and Whaller, 1970). Thus, rhizobia capable of successfully establishing a symbiosis under moisture-deficit environments may also require tolerance to high nitrate levels.

The higher levels of endogenous ABA in roots of many legumes during water defi- 
cit may be one of the reasons for poor nodulation (Williams and Sicardi-de-Mallorca, 1984). Many legumes produce abnormally thick root hairs in dry soil, and rhizobia fail to initiate nodulation in such root hairs (Sprent, 1971). Also, moisture deficit retards infection of the root hair and reduces the number of infection threads, leading to poor establishment of symbioses in dry soils (Graham, 1992). Thus, legume genotypes are needed that can produce normal root hairs under low soil moisture levels, in addition to the need for rhizobia capable of infecting root hairs under moisture deficit (Sprent, 1971).

\section{b. Nodule Functioning}

Once the legume-Rhizotium symbiosis is established, nodule function depends on the ability of the host to supply photosynthates, nutrients, and water to the nodules. This in turn is affected by the host plant water status. Although nodules are capable of obtaining water directly from the soil. much of it is supplied through the root $x y$ lem (Sprent, 1971). Even though the nodulation zone of the root system, which is usually $5 \mathrm{to} 1.5 \mathrm{~cm}$ deep. may trequently be subjected to intermittent water deficit, the host root system is capable of supplying water to nodules from deeper in the soil profile. thus to some extent protecting the nodules from severe moisture deficit (Johnson et al., $1981)$. Because the nodule surface is permeable to water and gases, a portion of the water supplied from deeper soil layers can be lost from the nodule surface, thus predisposing nodules to water deficit (Bennett and Albrecht, 1984). Identification of genotypes capable of forming functional nodules at deeper soil layers (e.g., below a depth of 15 $\mathrm{cm}$ ) would be desirable, as would rhizobial strains capable of thriving at these depths.

With inadequate water supply, nodules lose water from their surface, and may inevi- tably shrink (Pankhurst and Sprent. 1975). restricting gaseous diffusion and reducing the rate of nitrogen fixation (Sprent, 1976; Williams and Sicardi-de-Mallorca, 1984). The water content of nodules is positively correlated with nitrogen-fixing ability in soybean, $P$. v'ulgaris, Trifolium repens, and lupins (Engin and Sprent, 1973; Sprent, 1976; Djekoun and Planchon, 1991). Nitrogenase activity in the tropical legumes groundnut and cowpea recovered following a droughtinduced decrease in nodule fresh weight of $40 \%$ (Rao and Venkateswarlu. 1987). On the other hand. in temperate legumes such as Lupinus arboreus, Vicia faha, T. repens, and $P$. vulgaris, water-deficit effects are reversible, hut only if the decrease in nodule fresh weight is $<25 \%$ of the control (Engin and Sprent, 1973; Sprent, 1976).

Recovery of nitrogen-fixing ability in existing nodules, when water deficit is relieved. depends on the severity of stress. nodule morphology (determinate or indeterminate nodules). OA capability of nodules, nodule formation mechanism (either on the root hairs or roots), and the ecological adaptation of the legume species (Venkateswarlu et al., 199()). Indeterminate nodules may have a greater recovery potential than spherical nodules in which rehydration of existing tissue is the only possibility unless new nodules are produced (Swaraj, 1987). Also, indeterminate nodules, like those of Vicia. Pisum, and Trifolium spp., have prolonged meristematic activity and are more resistant to low soil water potentials (Engin and Sprent, 1973: Swaraj. 1987) than spherical nodules, as in soybean, cowpea, and pigeonpea. which have limited meristematic activity (Sprent, 1971). Additionally, nodules that form close to the endodermis (as in V. faba and groundnut) are better able to resist periods of water deficit than superficially attached ones, as in T. repens or cowpea (Sprent, 1971). Nodules of some legumes, such as alfalfa, clusterbean (Cyamopsis tetragonoloba), and faba bean, can recover rapidly (Carter and 
Sheaffer, 1983), but those of pigeonpea (Sheoran et al., 1981) recovered only up to $85 \%$ after experiencing a mild water deficit of $-0.6 \mathrm{MPa}$. In legumes such as cowpea. mungbean. and black gram. nodule recovery is incomplete (Sprent, 1971). Thus, legume species vary in the ability of their $N_{2}$ fixation to recover from water deficit (Aparicio-Tejo et al., 1980).

Nitrogen-fixing activity declines in many legumes as the crop approaches maturity (Lawn and Brun. 1974). Nearly 60 to $70 \%$ of the leaf nitrogen is diverted to the pod-filling process and this leads to early cessation of photosynthetic ability, termed as a "self-destruction" process (Sinclair and deWit, 1975). Minimal nitrogen fixation occurs during seed filling in legumes like cowpea. soybean, and black gram. further aggravating the self-destruction process (Cure et al., 1985). Terminal moisture deficit. common in long-duration legumes sown during a rainy season and on receding soil moisture during a postrainy season. could accelerate this destruction (Cure et al., 1985). Therefore, the ability to extend nitrogen-fixation activity into the reproductive growth phase under-moisture limited environments could play a major role in improving grain legume productivity in these environments.

\section{GENETIC IMPROVEMENT STRATEGIES}

\section{A. Screening and Selection}

Characterization of the drought environment of the target production region is a first and crucial step in undertaking a genetic improvement program aimed at improving yield and yield stability in drought-prone environments (Campbell and Diaz, 1988: Robertson, 1988). Production environments can be grouped into subsets of environments using canonical variate analysis (cluster analysis) (Seif et al., 1979; Shorter and
Hammons. 1985: Malhotra and Singh, 1991). by considering such factors as soil water balance. temperature regimes, the potential evapotranspiration of the growing environment (using long-term climatic data), or hased on $G \times E$ interactions (Seif et al.. 1979). Thus, mean and variance of moisture deficits likely to occur during the growing season and length of the growing season can be calculated. This will assist in estimating the intensity and duration of stress the crop is likely to experience, and at which crop growth stage, thus guiding development of relevant screening methodology for evaluating germplasm lines. This strategy also will help in identifying the environments with similar drought patterns, to guide multilocational testing of genotypes developed for specific drought patterns. Recent development of GIS techniques allows for computerized mapping. and thus ready visualization, of such iso-drought environments.

In most cases, screening for drought resistance involves evaluating germplasm lines under field conditions with and without irrigation. Yield. its components, and total dry matter are normally estimated. Line source urrigation is also used to evaluate germplasm lines under a gradient of water deficit (Hanks et al., 1976). Moisture response curves are generated by regressing the yield of individual entries against water applied or environmental yield, to calculate the stability of a genotype across a range of moisture availabilities using the stability analysis procedures of Finlay and Wilkinson (1963) and Eberhart and Russell (1966). Line source irrigation studies with groundnut showed that genotypes with stability and high mean yield could be identified in early and mid-season drought patterns, but not in those drought patterns where genotypic sensitivity is negatively correlated with yield potential (Nageswara Rao et al., 1989; Singh et al., 1991).

Yield stability analysis has been suggested to define drought resistance in terms 
of yield (Finlay and Wilkinson, 1963; Eberhart and Russell, 1966), provided that the major component of variation in the environmental index could be attributed to the water regime. Stability of yield across environments could be represented by the slope of cultivar yield regressed on the environmental index (mean site yield). However. this approach does not consider the confounding effects of phenology on yield or the effects of yield potential on the slope of the regression and hence on the intercept and drought resistance. Fischer and Maurer (1978) proposed a drought susceptibility index. based on relative yield, to account for the confounding effects of yield potential of genotypes. To account for time to flowering. associated drought escape, and yicld potential. Bidinger et al. (1987a,b) proposed a drought resistance index (DRI). in which DRI is hased on the residual variation in grain yield adjusted for experimental error. The index is positively correlated with yield under drought, and independent of yield potential and time to flowering.

\section{B. Difficulties Associated with Yield- Based Selection}

Crop yield is the outcome of many processes occurring at different time scales and levels of integration (Passioura, 1983, 1992). Also, a character such as drought resistance is complex if measured as crop yield because of the many possible physiological. morphological, and biochemical factors related to drought resistance. Plant characters that intluence performance have differing opportunities for expression in different years (Ceccarelli et al.. 1991). Selection for drought resistance based on yield alone may not bring the required genetic shift in specific physiological attributes as different mechanisms would have different opportunities for expression under different conditions. Genetic gains made in one season may be lost in subsequent seasons due to the variability in the time, duration, and intensity of moisture deficit across years. Thus, screening and selection based entirely on yield or yield derived indices may be of limited value for genetic improvement in drought environments (although this is the criterion generally used), as the genotypic variance component is low compared with environmental and $G \times E$ variance under these conditions (Rosielle and Hamblin. 1981: Johnson and Geadelmann, 1989).

Adaptation to nondrought factors te.g.. photoperiod, temperature, pests, diseases, etc.) may have an overriding effect on yield, thus masking potentially superior drought resistance attributes of germplasm lines (White, 1988). Even though landraces may possess a higher degree of drought resistance due to their better adaptation to drought environments compared with improved cultivars. this would not necessarily translate into higher drought resistance ratings when cvaluations are based on yield or yicld-derived indices alone due to their possible poor adaptation to the location where they were evaluated or their inherent low harvest indices (Ehdaic and Waines, 1988: Ehdaie et al.. 1988: Blum et al., 1992). Yield-based indices may result in the development of genetic materials that have adaptation to the selection site but have a limited role in developing genetic stocks or varieties suitable for other is()-drought locations. The probability of success in transferring a multigene adaptation, such as drought resistance, by breeding could, however, be improved by selecting for important components of the resistance mechanisms involved rather than selecting at a functional phenotypic level (Blum, 1979; O’Toole and Chang, 1979: Jordan and Miller, 1980).

The approach that is put forward for consideration is conceptually different from the "ideotype" approach proposed by Donald (1968). wherein an ideotype is defined by a 
set of morphophysiological attributes that are thought to improve the genetic yield potential for a given crop species across a number of production environments. This could be termed as the "static ideotype" approach (Lawn and Imrie, 1991). One of the most serious criticisms of this "static ideotype" approach is that it does not take into account the $\mathrm{G} \times \mathrm{E}$ interaction. and this denies the breeder the opportunity to exploit specific adaptation, in this case the moisture-availability patterns during the growing season (Lawn and Imrie. 1991). The limitations associated with this approach are thoroughly discussed by Marshall (1991). Sedgley (1991), and Lawn and Imrie (1991). thus they are not repeated here.

Given the range and patterns of moisture stress that can occur in drought-prone environments of any given crop production region, a wide spectra of biological models or desired physiological ideotypes need to be developed to suit the specific requirements of various target production environments. This could be termed as "dynamic crop plant ideotypes". wherein it is implicitly recognized that an optimal combination of morphological, phenological, and physiological traits may differ from one production environment to another (Lawn and Imrie, 1991: Sedgley. 1991) and would be continuously subjected to validation during the course of a breeding program. Also, for physiological traits that are of a quantitative nature, such as TE or OA, in which the degree of expression is on a continuous scale, it is to be recognized that the degree of desired level of expression of these traits will vary according to the needs of the target environments. For instance, in durum wheat drought evaluation trials, it was noticed that most of the highyielding durum genotypes under drought stress had an intermediate range of residual transpiration rate (excised leaf water loss rate), whereas genotypes at either extreme did not yield well, although there is gener- ally a negative correlation between grain yield under drought and residual transpiration rate (Clarke et al.. 1989). This underlines the need for choosing the optimum level of expression of a desired physiological trait, and this optimum expression will vary according to the needs of the target environment. Most ideotype breeding has been preoccupied with extreme morphological characters, such as the uniculm chacteristic in wheat or barley, without realizing the limitations in various production environments (Sedgley. 1991). Also. component ideotypes of a crop species in a given target production environment need to be considered to ensure a balanced set of objectives in a breeding program and also the possibility of interactions between differing ideotype characters such as traits associaled with morphology. phenology, canopy structure, and disease resistance (Sedgley, 1991).

Thus, breeders are expected to tailor crop plants for adaptation to specific environments where moisture deficits are well characterized. Conceptually, this is an important deviation from the traditional vicw of plant breeding, which is normally to develop varieties adapted to a wide range of environments. This could lead to development of genotypes/varieties that could optimize exploitation of specific adaptation in given target production environments.

There are a number of advantages of addressing this problem through a physiological genetic approach, including

1. Development of conceptual biological models (dynamic ideotypes), which are defined in terms of combinations of traits that suit the requirements of a target production system.

2. Selection focused on specific physiological attributes that will result in the identification or development of genetic stocks possessing various levels of expression of a given attribute. 
3. By defining the biological model at the beginning of a breeding program, the team of scientists involved will have a better comprehension of what they are specifically looking for, rather than treating adaptation to moisture-deficit environments as one single component. This also helps in evaluating the existing locally adapted varieties for traits (using biological models as a basis) that they may be lacking: thus, the genetic improvement of these existing adapted varieties could be focused on certain physiological attributes considered worth improving. The breeding methodology and selection criteria could then he well defined, so as to improve the chances of genetic gains.

4. The various genetic materials that are identified as having useful physiological attributes, and the levels of expression of a given attribute in various genetic materials, can be entered into a database. These genetic stocks would then be available for other breeding programs in other agro-ecological zones.

By following the above approach, the plant breeder then can more systematically transfer genes related to particular relevant traits and accumulate these in a step-wise manner instead of awaiting their coincidence. Such an analytical approach, however, requires considerable knowledge of the physiological and genetic basis for drought resistance. The subsequent sections are focused toward implementing this approach.

\section{Trait Identification and Evaluation}

The word "trait" invokes several considerations: one is the level of integration or hierarchy of plant organization that should be addressed. Generally, plant breeders do not face the problem of choosing between levels of integration, but a physiologist continuously faces this choice (Acevedo and Ceccarelli, 1989). Because increased expression of most drought-resistance mechanisms reduces the potential for maximum yield. an optimum level of expression is required for each situation (Jones, 1980). The major difficulty in determining this optimum is the unpredictability of the weather, although the capacity of the plant to sense and respond to changes in the environment and water supply is also important. Given the detailed knowledge of the environment and water availability during the course of a season. it is possible, at least in principle. to calculate retrospectively the kind of physiological and morphological attributes required to maximize yield.

The steps to follow before a particular trait can be recommended for use in a breeding program aimed at improving drought resistance are

1. Develop a hypothesis and validate the potential contribution of a particular trait

2. Search for genotypes with high levels of expression of the desirable trait

3. Determine the mode of inheritance of the trait

4. Develop rapid and efficient screening methods for segregating populations

5. Incorporate the trait into agronomically superior genotypes

The greatest obstacle to a physiological approach is production of convincing evidence linking high levels of expression of a trait to improved crop performance under drought. Compensatory effects and interactions with the environment make it very difficult to assess the value of particular physiological attributes in improving drought resistance (Jordan et al., 1983; Clarke et al., 1984; Ceccarelli et al., 1991; Marshall, 1991). Also, little information is available on how different physiological attributes (mechanisms) interact in determining a given level 
of drought resistance (Jones, 1980). The effectiveness of a particular trait will depend on the nature of the drought stress occurring in a particular area and growing season (Garrity et al., 1982; Ceccurelli et al., 1991). Each physiological pathway to maximization of yield will be effective only when the genotype. environment. and the consequent physiological pathway are correctly matched.

A common approach for assessing the value of traits is by means of isogenic lines or populations (genotypes with similar genetic backgrounds but contrasting in the expression of a particular trait) (Garay and Wilhelm. 1983; Johnson et al., 1983: Richards et al.. 1986: Grumet et al.. 1987). Such an approach has a time scale of years, as it depends on finding significant heritable variation for the stress response trait. and then a crossing (prebreeding) program to incorporate different levels of trait expression into a uniform genetic background. Another limitation associated with this approach is that traits may be expressed differently in different genetic backgrounds. If so, the information from isogenic lines may be of limited value as plant breeders would like to be able to use the trait in different genetic backgrounds depending on the target environment (Ceccarelli et al.. 1991: Wallace et al., 1993). Also, pleiotropic effects could obscure the expression of the physiological trait in different genetic backgrounds.

Different combinations of a given set of traits may result in a similar level of drought resistance (Acevedo and Ceccarelli, 1989; Ceccarelli et al.. 1991). One way to overcome these problems while assessing the value of a trait is through divergent selection for different traits related to drought resistance (Acevedo and Ceccarelli, 1989). This has a number of advantages over the isogenic line approach: (1) it offers the possibility of assessing the role of individual traits as well as a combination of traits in randomly assorted genetic backgrounds; (2) it generates information on realized heritability of traits under contrasting environments: and (3) it allows a comparison of the selection efficiency between a yield-based is. a trail-based approach.

Simulation modeling is another possible approach to assess the value of a trait (Meyer. 1985: Muchow et al. 1991: Shorter et al.. 1991: Hunt. 1993; Muchow and Carberry. 1993). Simulations are performed with the trait present or absent to varying degrees, with all other factors held constant (Jones and Zur. 1984: Hunt, 199.3). Also, simulation models play an important role in suggesting hypotheses on which traits are worth pursuing and validating (Ceccarelli et al.. 1991). Growth simulation models such as BEANGRO (Hoogenboom et al., 1988). PEANUTGRO (Boote et al., 1985), and SOYGRO (Jones and Zur, 1984) are being used to predict the integrated effects of different mechanisms in the context of variable climatic conditions and agronomic practices. However, the usefulness of simulation modeling depends on the availability of sufficiently robust models for the particular crop and sufficient understanding of the trait and its mode of operation. To our knowledge, in the case of pigeonpea. chickpea. and mungbean at least, such models are not in such a sufficiently advanced state to use for this purpose.

\section{Physiological Mechanisms - The Underlying Philosophy}

Plants are highly integrated organisms, and when stress disturbs processes in the system, a variety of control mechanisms are brought into play to adjust other processes so as to maintain functional balance and thus cope with adversity (Hsiao and Acevedo, 1974). It is important, however, to differentiate the physiological mechanisms that assist the plant to survive and grow under moisture-limited environments from mere physiological consequences of reduced growth and injury. Most of the physiological 
information available only describes the consequences rather than the causes or mechanisms that could contribute to maintained productivity under moisture deficit (Jones and Corlett, 1992). Also, when genotypes are evaluated for their metabolic efficiency under moisture-deficit environments, care should be taken to separate other factors, such as differences in plant water status, that could mask metabolic differences (Singh et al., 1973).

Plants are homeostatic systems with much coupling and buffering between processes, and with a set-point for the survival of the genome (Hardwick, 1988). In engineering terms, "the "critical trait" in a homeostatic system is not the rate of any one process, rather it is the determination of the sel-point" (Cram, 1983). Thus, it may not be easy to define which of the physiological mechanisms is the most critical in determining drought resistance in a given crop. Many reports are available on nonlinear strongly buffered plant responses, such as starch in the pod walls of soybean (Fader and Koller. $1985)$ and stems of Vigna radiata and $V$. mungo (Muchow and Charles-Edwards. 1982). Physiological selection criteria involve two domains of drought stress: the domain when stressed plants maintain a positive carbon balance, and the domain when plants enter a situation of negative carbon balance and are merely surviving. Selection for resistance in the first domain involves factors that sustain transpiration, efficient moisture extraction, high WUE. and high HI (Blum. 1988). Selection for resistance in the second domain involves the conservation of viable meristems and the capability of plants to subsequently recover and produce a reasonable yield.

\section{E. Conceptual Framework for a Physiological Genetic Approach}

The underlying theme of any crop improvement program is to develop cultivars capable of utilizing the target production environment to the optimum extent genetically feasible. A clear conceptual framework is necessary for integrating the analytical approach of crop physiology into the pragmatic approach of breeding a crop for moisture-limiting environments. We believe that the conceptual models that could be used for the rainy season and postrainy season growing environments are different. In the first case, the crop growth model proposed by Duncan et al. (1978) would seem more appropriate and, in the second case, Passioura's (1977) model could be used. Although both models can explain and predict yield accurately, the choice of the model for a given environment is deternined by the ease with which components of the model can be measured. Although these frameworks are quite simple and broad. they nevertheless help focus on a wide range of physiological. morphological, and developmental attributes of possible significance to drought resistance and. furthermore. they help assess the importance of these attributes (Passioura, 1977. 1992).

Duncan's (Duncan et al., 1978) crop growth model describes yield as:

$$
\mathrm{Y}=\mathrm{C} \times \mathrm{D}_{\mathrm{r}} \times \mathrm{p}
$$

where, $\mathrm{Y}=$ yield of pod or seeds $\left(\mathrm{kg} \mathrm{ha}{ }^{-1}\right)$ : $\mathrm{C}=$ mean crop growth rate $\left(\mathrm{kg} \mathrm{ha}{ }^{1}\right.$ day $\left.^{-1}\right)$; $D_{r}=$ duration of reproductive growth (days): $\mathrm{p}=$ mean fraction of crop growth rate partitioned to yield $(Y)$. This can be derived by dividing the mean rate of yield accumulation ( $\mathrm{Y} / \mathrm{D}_{\mathrm{r}}$ ) by mean crop growth rate $(\mathrm{C})$.

Passioura (1977) considers that, under moisture-limited environments, grain yield is determined by the relationship:

$$
\mathrm{Y}=\mathrm{T} \times \mathrm{TE} \times \mathrm{HI}
$$

where. $\mathrm{Y}=$ yield $\left(\mathrm{kg} \mathrm{ha}^{-1}\right) ; \mathrm{T}=$ amount of water transpired $\left(\mathrm{mm} \mathrm{ha}^{-1}\right)$; TE $=$ transpiration efficiency $\left(\mathrm{kg} \mathrm{ha}^{-1} \mathrm{~mm}^{-1}\right) ; \mathrm{HI}=$ harvest index. 
Each subcomponent in both models is an integrated function of a number of morphological and physiological attributes (Hardwick, 1988). The relative importance of these attributes and their expression in the optimum exploitation of a target production environment (thus in determining yield) varies across environments. Thus, one could use this analytical framework to identify and assess the limiting factors and the physiological attributes necessary to optimize the various components of the model in order to best exploit a given production environment. Novel approaches are available to quantify the shoot growth rates and partitioning on a thermal time basis on a large scale, using nondestructive methodologies (Williams and Saxena. 1991). Traits (morphological and physiological) should be evaluated in terms of their functional relationship and the strength of their correlations to one of these components (Kramer. 1980): Ludlow and Muchow. 1990) having maximum association with yield in the growth model.

We believe that a more directed physiological approach is relevant to genetic improvement considerations. The two main approaches that we see for achieving this are the "black box" and "physiological ideotype" approaches. For the sake of convenience, we discuss these two approaches separately, but both could form components of an integrated approach of a crop improvement program. The "black box" approach leads to the identification of potential traits and genetic stocks that would form the building blocks for developing a physiological ideotype, which acts as a conceptual framework for the genetic improvement program.

\section{Black Box Approach}

The black box approach proceeds from established phenotypic differences, that is, from differences in drought resistance, to the underlying morphological, physiological, and biochemical mechanisms (Fischer,
1981). Genotypes are evaluated in the target environment to establish genetic differences in drought resistance based on yield or yieldderived selection indices. Multivariate statistics can be employed to identify potentially useful combinations of traits that correlate with yield or yield-derived indices (White. 1988). Once a source of drought resistance is identified in the cultivated species or its wild relatives. the next step is to understand the mechanisms underlying drought resistance. Simple and effective means of screening segregating populations for specific physiological or morphological attributes must he developed for a successful breeding program. Partitioning differences among groundnut genotypes in drought environments have been reported consistently and are attributed to differences in drought resistance (Greenberg et al., 1992). However, it is important to understand different strategies that genotypes adopt in their reproductive hehavior, which reflects their differences in partitioning and thus drought resistance: once this is understood, it then will be much easier to choose strategies that suit the larget environment. For example, groundnut genotypes differ in their pod development attributes; genotypes such as TMV 2 and Robut 33-1 can produce and fill pods at a moderate, but constant, rate irrespective of the changes in the intensity of the drought (Harris et al.. 1988; Chapman et al., 1993a,b.c). This adaptation is best suited for terminal drought stress environments where the growing season is more predictable. Thus. the ability to maintain reproductive development in dry soils may play an important role in determining their adaptation to these environments. In contrast, genotypes such as Kadiri-3 continue peg initiation during drought periods, but pod development stops until moisture deficit is relieved (Harris et al., 1988). Therefore, this genotype is more suited to environments where the moisture deficit is intermittent and unpredictable during the growing season. 
Different adapted landraces or cultivars have evolved a variety of mechanisms that contribute to yielding ability under a given pattern of moisture availability. Genotypes attain a level of drought resistance through their own combinations of various physiological attributes. For instance, one genotype may attain a given level of drought resistance through its deep root system. whereas another may attain the same level of drought resistance through its higher TE. However, some genotypes may have both attributes. This was the case in groundnut. where higher TE was associated with increased root growth (Wright et al., 1994). However, in groundnut, TE is negatively correlated with HI (Hubick et al., 1988; Wright et al., 1988: Nageswara Rao et al. 1993). Thus, the same level of drought resistance expressed in terms of yield can be attained through either high partitioning ability or higher TE (Legumes Program. 1992). Soybean genotypes with deep rooting characteristics have relatively poor OA capability and the reverse is true for genotypes with shallow rooting characteristics (Cortes and Sinclair, 1986).

The underlying philosophy is that, although different genotypes may show the same level of drought resistance, they can attain this through different physiological mechanisms or attributes (Acevedo and Ceccurelli, 1989; Ceccarelli et al., 19911. These can be identified using the black box approach within the conceptual framework described earlier. This information will assist in identifying potential parents having complementary physiological attributes and also will help to direct selection in the segregating materials toward these specific physiological attributes. This approach may lead to development of genetic materials segregating for a higher level of drought resistance and also improve the chances of selecting for improved levels of drought resistance from these populations.

\section{Physiological Ideotype and Pyramiding Approach}

An ideotype is defined as "a hypothetical plant described in terms of traits that are thought to enhance genetic yield potential" (Donald, 1968: Rasmusson. 1991). A physiological ideotype for drought resistance could be defined in terms of specific physiological traits expected to contribute functionally to optimize yield production and stability under moisture-deficit environments. However, it is imperative that the climatic regime for which the plant is being designed be thoroughly understood because a single universal ideotype will not be adapted to all moisture-limited environments. Rather, many biological models will be required because the moisture-deficit environments are diverse (Wilson. 1981: Lawn and Imrie. 1991: Sedgley, 1991).

Conceptually, the physiological approach for improving drought resistance in crop plants should be to bring together various physiological trasts that complement each other in a pyramidic (building block) manner by selective incorporation of these traits into a single cultivar, that is, accumulation of several. probably independent. physiological mechanisms into a single cultivar. An analogy can be drawn from disease resistance breeding: horizontal resistance (defined as resistance to a number of physiological races of a disease) can be achieved by pyramiding different genes carrying resistance to individual physiological races into one cultivar (Parlevliet and Zadoks, 1977). This contributes to stability of the cultivar across years in disease-prone environments. The same concept also can be applied to drought resistance, whereby pyramiding of genes that regulate different specific physiological traits into a single cultivar could provide that cultivar with the necessary genetic means to respond to the different types of moisture deficit that it is likely to experience at different locations, sites, and years 
within a specific region. The various steps involved in this kind of approach are

1. Define the various physiological traits that have functional significance for productivity in a given crop under water limited environments using the conceptual models mentioned in Section IV.E, realizing that the trait requirements will vary depending on the target environment.

2. Establish the genetic variability and locate sources of high levels of efficiency for each physiological trait in the germplasm or its related wild spesies, that is, selection should be directed loward the individual components of drought resistance on a trait-by-trait basis, irrespective of the yielding ability of the genolypes carrying these traits. This can be done effectively through establishing physiological nurseries for screening specific traits similar to disease-screening nurseries.

3. Establish the genetic basis for each physiological trait under consideration by studying its inheritance, and estimating heritability to determine the feasibility of using that particular trait in a breeding program.

4. Develop genetic markers, such as random amplified polymorphic DNA (RAPD) and restriction fragment length polymorphisms (RFLP) markers, if easily identifiable morphological, physiological, or other markers are not readily available for each physiological trait, as this can increase the efficiency of selection from segregating materials.

5. Identify genotypes for each physiological trait that have good combining ability.

6. Incorporate relevant traits into agronomically acceptable backgrounds.

Information generated through this exercise could be stored in a database and made available to plant breeders interested in in- corporating drought resistance components into their breeding programs. This is similar to the databases available for morphological traits from the germplasm evaluation programs at the Consultative Group for International Agricultural Research (C.GIAR) Centers.

\section{Development of Genetic Markers for Physiological Traits}

Most physiological traits are controlled by one too many genes located throughout the chromosome complement. Each of the individual genes of such a polygenic system contributes a small positive effect to the trait of interest. Clear dominance is not exhibited, and the phenotype has a large component of environmental variance. All these characteristics conspire to make physiological traits very difficult to analyze. Thus, conventional Mendelian methods of analysis. which are suitable for traits controlled by a single or a few genes, cannot he applied to analysis of these physiological traits. This is one of the reasons why physiological traits have not been used extensively in drought resistance breeding programs, although several physiological traits with functional significance to production under moisture-limited environments have been identifjed by crop physiologists (Ludlow and Muchow, 1990) and some breeders have advocated their judicious incorporation into breeding programs (Rasmusson, 1991).

Development of genetic markers, such as RAPD and RFLP, for each of the physiological traits contributing and incorporating drought resistance should increase the efficiency of selecting these physiological traits and incorporating them into an improved cultuvar (Paterson, 1991). It is possible to analyze complex polygenic characters such as physiological traits as ensembles of single Mendelian factors using genetic markers (Tanksley et al., 1989). Because 
RAPD and RFLP markers can be used to simultaneously follow the segregation of all chromosome segments in a crossing program, the basic idea is to detect correlations between the physiological trait and specific chromosome segments marked by RAPD or RFLP. If correlations exist, then the inference is that the chromosome segment must be involved in the quantitative trait. The difficult part in this procedure is establishing correlations between the trait and specific chromosome segments. The RAPD and RFLP markers can be easily scored, but the physiological trait must be characterized in the conventional fashion (Tanksley et al., 1989; Rafalski et al., 199|). Once this most difficult process is completed, and specific chromosome segments are implicated in the rait, plants carrying RAPI) and RFLP markers with a positive effect on a quantitative trait can be selected from a segregating population. This is possible because single plants can be easily seored for several RAPD or RFL.P markers simultaneously. frec from environmental influence or gene interactions. Carbon isotope $\left({ }^{12} \mathrm{C}\right)$ discrimination was satisfactorily predicted from three RFLPs in tomato (Martin et al., 1989). Similarly, osmotic adjustment in sorghum is reported to be linked with two RAPD markers (Ludlow et al.. 1993). Thus, the analysis of quantitative traits, such as physiological characters. can be carried out by conventional Mendelian analysis. However. this approach may be limited to a few selective traits considering the practical difficulties involved in developing these genetic markers for a given physiological trait and also the limitations associated with generating large numbers of early segregating materials to get a desired level of recombination if one has to handle several traits simultaneously in a breeding program (Marshall's "tyranny of numbers") (Marshall. 1991).

\section{Limitations Associated with Ideotype Concept and Concluding Remarks on Physiological Genetic Approach}

The concept of "dynamic physiological ideotypes" that is introduced here could overcome some of the conceptual problems associated with the static ideotype in guiding the crop improvement programs to exploit specific adaptation of genetic mechanisms to well-defined, drought-prone target production systems. Nevertheless, some of the inherent conceptual and practical difficulties associated with the static ideotype approach will still persist. Some of the most important ones are

1. The challenges associated with characterization of the target drought environment, as this would determine the appropriate biological model(s) required for a crop variety.

2. Difficulties associated with determining the appropriatc biological model for a target environment, given the conceptual difficulties such as the unlikelihood of these being a single optimum biological model for a given target environment: a number of biological models may have the same level of efficiency. This opens up more options to the breeders to choose the right combinations of traits. taking into consideration the practical difficulties of incorporating certain physiological traits.

3. The difficulties associated with finding appropriate genetic variability for a given physiological trait, and the limitations associated with developing the appropriate screening methodology: the amount of financial, personnel, and technological resources required to operate such a breeding program for incorporating specific traits could compound these problems. 
4. Interrelationships among individual traits and compensation among traits to maintain the internal metabolic homeostasis may prevent the breeders from realizing the desired impact of an improved metabolic efficiency on phenotypic expression.

5. Pleiotropy (i.e.. one gene affecting more than one character) (e.g.. the negative relation between $\mathrm{TE}$ and $\mathrm{HI}$ in groundnut) could obscure expression of an important trait and in realization of the expected improvement of efficiency of the phenotype.

6. Genetic background effects, such as when desirable genes express only in inferior parents.

Certainly the physiological-genetic approach is not an easy solution to all of the problems associated with genetic improvement programs aimed at drought-prone environments. However, the dynamic physiological ideotypes approach could provide a sound conceptual framework for better defining breeding objectives, and thus would assist in directing genetic improvement programs. This can guide breeders in directing their efforts more specifically toward selective traits or combinations of traits, thus providing more options to overcome some of the practical and conceptual limitations associated with the trait-based approach. Breeders may benefit from the trait-based approach by specifying the desired goal of phenotype for each trait, thus goal setting and generating of hypotheses within breeding programs would induce the necessary scientific temper (Rasmusson, 1991), which we believe would certainly be beneficial to the program. However, the physiological-genetic approach that is advocated here should not be seen as an alternative or substitution to the empirical approach in which selection is based on yield or yield-derived indices; rather, it should be seen as complementary to the empirical ap- proach. with the awareness of the practical advantages associated with the latter approach. There are difficulties associated with the trait-based approach and practical limitations in implementing this approach. These have been comprehensively highlighted by Lawn and Imrie (1991). Marshall (1991). Rasmusson (1991), and Sedgley (1991).

However, identification and characterization of genetic stocks that have key metabolic efficiency traits (such as OA. TE. and the ability to remobilize preanthesis-stored nonstructural carbohydrate reserves for grain (illing), and by introducing such traits into suitable adapted genetic backgrounds, could have a major impact on crop production. and thus crop adaptation to drought-prone environments. One of the most successful examples of a trait-based approach is how "Norin-10" dwarfing genes revolutionized the genetic yield potential of wheat all over the world (Rasmusson, 1991). Thus, with the potential for widespread use of improved genetic stocks in research and breeding programs, and by sharing the work of incorporating specilic physiological traits into superior genetic backgrounds, it should be possible to develop "physiological trait collections", just as there are collections of genetic slocks and collections of genes for disease resistance (Rasmusson, 1991). This would be definitely advantageous for longterm crop improvement needs and, keeping in mind that the environmental conditions. particularly rainfall patterns of a given agroecological production zone, are continuously changing over time, thus necessitating the development of new biological models to cope up with changing physical environments.

\section{FUTURE OUTLOOK}

It is difficult to quantify the impact of moisture deficits on crop yield losses on a 
global scale, considering the transient nature of the problem in the many differing agroecological production environments. Perhaps the complexity could be minimized by better defining the target production systems in terms of geographical boundaries and soil, climatic, and cropping systems characteristics therein. Then, better directed genetic improvement may be possible either by an empirical approach, or by incorporating specific physiological traits that would enhance drought resistance. Genetic strategies can be optimized only to help minimize the impact on legume productivity at moderate levels of moisture deficit that are common in rain-fed production systems. The level of improvement required and the feasibility of realizing the desired improvement will vary from crop to crop. This will depend on the inherent ability of the crop to tolerate dry environments, the amount of genetic variability in physiological components of drought resistance, and the availability of scientific and economic resources for deployment to crop improvement. In the more developed countries, improving drought resistance (average productivity) over a time span (e.g., 10 to 20 years) may be realistic and acceptable. However, in less-developed countries, survival of the subsistence farmers and the general economy depends entirely on minimizing the probability of crop failure. This can to some extent be addressed by adopting short-term strategies of incorporating various physiological defense mechanisms into crop cultivars to allow a certain level of realized yield in a more reliable manner. However, this is likely to be accomplished only at the expense of yield potential. Despite the difficulties, the ultimate test of any drought improvement endeavor is the demonstration of improved yield in drought situations in farmers fields. Quantification of this impact needs to be factored into the overall genetic improvement program to allow assessment of the efficiency of that program. and hence guide future such efforts.
The previous 2 decades of research on drought resistance in legumes have led to a vastly improved understanding of the various physiological mechanisms and strategies crop plants have evolved during the course of their adaptation to moisture-deficit environments. This has led to a better conceptualization of the biological models that are appropriate to various drought-prone environments. Also, our ability to define and characterize the target environment has improved recently with the availability of soilwater balance models and techniques such as GIS. We believe that. if properly integrated, these recent developments of physically characterizing the environment and appropriate biological models could form the basis for tailoring genotypes using physiological. genetic, breeding. and management strategies for better utilization of droughtprone target production environments.

\section{ACKNOWLEDGMENTS}

The authors thank Drs. D. J. Flower, F. B. Lopez. J. H. Williams, and F. R. Bidinger for their helpful comments. discussions, and suggestions during the preparation of this manuscript.

\section{REFERENCES}

Acevedo, E. and S. Ceccarelli: Role of physiologist-breeder in a breeding program for drought resistance. In: Drought Resistance in Cereals. (pp. 117-139). Baker, F. W. G., Ed.. CAB International. U.K. (1989).

Ackerson, R. C.: Osmoregulation in cotton in response to water stress. Plant Physiol. 67: 489-493 (1981).

Aparicio-Tejo, P. M., M. F. Sanchez-Diaz, and J. 1. Pena: Nitrogen fixation, stomatal response and transpiration in Medicago sativa, Trifolium repens, and $T$. subterraneum under water stress and recovery. Physiol. Plant. 48: 1-4 (1980). 
Arihara, J., N. Ae, and K. Okada: Improving responses of chickpea and pigeonpea to phosphorus application in Vertisols and Alfisols. In: Phosphorus Nutrition of Grain Legumes in the Semi-Arid Tropics. (pp. 157-165). Johansen, C.. K. K. Lee. and K. L. Sahrawat. Eds.. International Crops Research Institute for the Semi-Arid Tropics. (ICRISAT). Patancheru. A. P., India (1991).

Arihara, J., N. Ae, and K. Okada: Root development of pigeonpea and chickpea and its significance in different cropping systems. In: Phosphorus Nutrition of Grain Legumes in the Semi-Arid Tropics. (pp. 183-194). Johansen. C.. K. K. Lee, and K. L. Sahrawat, Eds.. International Crops Research Institute for the Semi-Arid Tropics. Patancheru, A.P., India (1991).

Asay. K. H. and D. A. Johnson: Breeding for drought resistance in range grasses. lowa $S t$. J. Re's. 57: $441-444$ (198.3).

Ashraf, M. and F. Karim: Screening of some cultivars/lines of black gram (Vigna mungo L. Hepper) for resistance to water stress. Trop. Agric. (Trinidad). 68: 57-62 (1991).

Austin, R. B., J. A. Edrich, M. A. Ford, and R. D. Blackwell: The fate of dry matter, carbohydrates and ${ }^{14} \mathrm{C}$ loss from leaves and stems of wheat during grain filling. Ann. Bot. 41: 1309-1.321 (1977).

Babalola. O.: Water relations of three cowpea (Vigna unguiculata L.) cultivars. Plant Soil. 56: 59-69 (1980).

Baldochi, D. D., S. B. Verma, and N. J. Rosenberg: Water use efficiency in a soybean field: influence of plant water stress. Agric. Forest Meteorol. 34: 53-65 (1985).

Barnes, D. K.: Managing root systems for efficient water use: breeding plants for efficient water use. In: Limitations to Efficient Water Use in Crop Plants. (pp. 127-136), Taylor, H. M., W. R. Jordan, and T. R. Sinclair, Eds., American Society of Agronomy, Madison, Wl (1983).
Begg. J. E.: Morphological adaptations of leaves to water stress. In: Adaptations of Plants to Water and High Temperature Stress. (pp. 3.3-42), Turner. N. C. and P. J. Kramer. Eds., Wiley, New York (1980).

Bell, M. J. and G. Harch: Effect of photoperiod on reproductive development of peanut ( $A$ ra(his hypogas a L.) in a cool sub-tropical environment. I. Field studies. Aust. J. Agric. Res. 42: 11.3.3-1149 (1991).

Bennett, J. M., K. J. Boote, and L. C. Hammond: Alterations in the components of peanut leat water potential during desiccation. J. Exp. Bot. 32: 10.35-1()43 (1981).

Bennett. J. M. and S. L. Albrecht: Drought and flooding effects on $\mathrm{N}$, fixation, water relations and diffusive resistance of soybean. Agron. J. 76: 7.35-740) (1984).

Berninger, F. and P. Hari: Optimal regulation of gats exchange: evidence from field data. Ann. Bot. 71: 1.35-140)(1993).

Berry. J. A.: Adaptation of photosynthetic processes to stress. Scicnce 188: 664-650 (1975).

Bewley. J. D.: Physiological aspects of desiccation tolerance. Annu. Rev. Plamt Physiol. 30: 195-2.38 (1979).

Bharadwaj. S. N., P. N. Sharma, and V. Nath: $V$ arietal differences in drought tolerance of field pea (Pisum sativ'um L. Var. arvens poir). Ind. J. Agric. Sci. 41: 894-900 (1971).

Bidinger, F. R., R. B. Musgrave, and R. A. Fischer: Contribution of stored pre-anthesis assimilate to grain yield in wheat and barley. Nature. 270: 431-433 (1977).

Bidinger, F. R., V. Mahalakshmi, and G. D. P. Rao: Assessment of drought resistance in pearl millet (Pennisetum americanum $\mathrm{L}$. Leeke). II. Estimation of genotype response to stress. Aust. J. Agric. Res. 38: 49-59 (1987a).

Bidinger, F. R., V. Mahalakshmi, and G. D. P. Rao: Assessment of drought resistance in 
pearl millet (Pennisetum americanum $\mathrm{L}$. Leeke). 1. Factors affecting yields under stress. Aust. J. Agric, Res. 38: 37-48(1987h).

Bingham, J.: Varietal response in wheat to water supply in the field. and male sterility caused hy a period of drought in a glasshouse experiment. Ann. Appl. Biol. 57: 36.5-377 (1966).

Black, C. R., D. Y. Tang. C'. K. Ong, A. Solon. and L. P. Simmonds: Effect of soil moisture stress on the water relations and water use of groundnut stands. Nen' Phytol. 100): 31,3$328(198.5)$

Blum, A., W. R. Jordan, and G. F. Arkin: Sorghum root morphogenesis and growth. II. Manifestation of heterosis. (rop) Sci. 17: $15.3-157$ (1977).

Blum, A.: Genetic improvement of drought resistance in crop plants: a case for sorghum. In: Stress Physiology in Crop Plants. (pp 429-445), Mussell. H. and R. C. Staples. Eds., Wiley. New York (1979).

Blum. A.: Breeding programs for improving crop resistance to walter stress. In: Crop Reactions to Water and Temperature Stressess in Humid, Temperate Climates. (pp. 26,3-275), Raper, C. D.. Jr. and P. J. Kramer, Eds. West View Press. Boulder. CO, (1980).

Blum, A. and A. Ehercorn: Cell membrane stability as a measure of drought and heat tolerance in wheat. (rop) Sci. 21: 43-47 (1981).

Blum, A.. H. Bojarkova, G. Golan, and J. Mayer: Chemical desiccation of wheat plants as a simulator of post-anthesis stress. l. Effects on translocation and kernel growth. Ficld Crops Res. 6: 51-58 (1983a).

Blum, A.. J. Mayer, and G. Golan: Chemical desiccation of wheat plants as a simulator of post-anthesis stress. Il. Relations to drought stress. Field Crops Res. 6: 149-155 (1983b).

Blum. A. and C. Y. Sullivan: The comparative drought resistance of landraces of sorghum and millet from dry and humid regions. Ann. Bot. 57: 835-846 (1986).

Blum, A.: Plant Breeding for Stress Environments. CRC Press, Boca Raton. FL (1988).

Blum. A.: Osmotic adjustment and growth of barley genotypes under drought stress. Crop Sci. 29: 230-23.3 (1989).

Blum. A.. G. Golan, J. Mayer. B. Simmena. L. Shpiler, and J. Burra: The drought response of landraces of wheat from the northern Negev desert in Israel. Euphytica. 43: 87-96 (1989).

Blum. A., G. Golan. J. Mayer. B. Simmena, and T. Obilana: Comparative productivity and drought response of semi-tropical hybrids and open-pollinated varieties of sorghum. $J$. Agric. Sci. (Camb.). 118: 29-36 (1992).

Boote, K. J., J. W. Jones. J. W. Mishoe, and G. G. Wilkerson: Modeling growth and yield of groundnut. In: Agrometeorology of Groundnut. (pp. 243-254). Sivakumar, M. V. K., and Virmani, S. M., Eds., International Crops Research Institute for the SemiArid Tropics, Patancheru, A.P. India (1985).

Bouslama. M. and W. T. Schapaugh: Stress tolerance in soybeans. 1. Evaluation of three screening techniques for heat and drought tolerance. Crop Sci. 24: 9.3.3-937 (1984).

Boyer. J. S. and H. G. McPherson: Physiology of water deficits in cereal crops. Adv: Agron. 27: 1-23 (1975).

Boyer, J. S.: Photosynthesis at low water potentials. Philos. Trans. R. Soc. London Ser. B. 21: $501-512(1976)$.

Boyer. J. S.: Plant productivity and environments. Science. 218: 44.3-447 (1982).

Boyer. J. S.: Subcellular mechanisms of plant response to low water potential. Agric. Water Manage. 7: 239-248 (1983).

Boyer. J. S.: Mechanisms for obtaining water use efficiency and drought resistance. In: 
Plant Breeding in the 1990.s. (pp. 181-20()). Stalker. H. T. and J. P. Murphy, Eds.. CAB International, U.K. (1992).

Briggs, L. J. and H. L. Shantz: The water requirements of plants. II. A review of the literature. USDA Bur. Plant Ind. Bull. No. 285: $1-96$ (1913).

Brockwell. J. and R. B. D. Whaller: Studies in seed pelletting as an aid to legume seed inoculation. II. Survival of Rhizohiom meliloti applied to medic seed sown in (o) clay soil. Anst. J. Exy. Agric: Anim. Hush. 10: $455-459(1970)$.

Brown. S. C., P. J. Gregory, P. J. M Cooper. and J. D. H. Keatinge: Root and shoot growth and water use of chickpea / ('icer arte'te'num) grown in dryland conditions: effects of sowing date and genotype. J. Agric. Sci. (C ( $(1) \mathrm{l})$.). 113: $41-49(1989)$.

Bunting. A. H. and D. L. Curtis: Local adaptation of sorghum varieties in northern Nigeria. Ahmadu Bello Linis. Samaru Res. Bull. No. $106(1970)$.

Bushby, H. V. A. and R. J. Lawn: Accumulation of partitioning of nitrogen and dry matter by contrasting genotypen of mungbean (Vigna radiata L. Wilceek). Aust. J. Agric. Res. 43: 1609-1628 (1992).

Buttery. B. R., C. S. Tan, R. I. Buzzell, J. D. Gaynor, and D. C. MacTavish: Stomatal numbers of soybean and response to water stress. Plant Soil. 149: 28.3-288 (1993).

Campbell, G. S. and R. Diaz: Simplified soilwater balance models to predict crop transpiration. In: Drought Research Priorities for the Dryland Tropics. (pp. 15-26). Bidinger, F. R. and C. Johansen, Eds., ICRISAT, Patancheru, India, (1988).

Carter, P. R., C. C. Sheaffer, and W. B. Voorhees: Root growth, herbage yield, plant water status of alfalfa cultivars. Crop Sci. 22: 425427 (1982).
Carter. P. R. and C. C. Sheatfer: Alfalfa response to soil water deficits. III. Nodulation and $\mathrm{N}_{\text {. }}$ fixation. Crop Sci. 23: 98.5-990 (198.3).

Castonguay, Y. and A. H. Markhart: Saturated rates of photosynthesis in water stressed leaves of common bean and tepary bean. Crop Si. 31: 1605-1611 (1991).

(eccarelli. S., E. Acevedo, and S. Grando: Breeding for yicld stability in unpredictable environments: Single traits, interaction between traits, and architecture of genotypes. Euphytica. 56: 169-185 (1991).

Chapman, A. L. and R. C. Muchow: Nitrogen accumulated and partitioned at maturity hy grain legumes grown under different water regimes in a semi-arid tropical environment. Ficld Crops Re's. 11: 69-79 (1985).

Chapman. S. C.: The Effect of Drought During Reproductive Development on the Yield of Cultivars of Groundnut (Arachis hypogelea L.). Ph.D. thesis, University of Queensland. Brisbane, Australia (1989).

Chapman. S. C.. M. M. Ludlow. F. P. C. Blamey, and K. S. Fischer: Effect of drought during early reproductive development on growth of cultivars of groundnut (Arachis hypogatea L..). I. Utilization of radiation and water during drought. Field (rops Res. 32: 193-210) (199.3a).

Chapman, S. C., M. M. Ludlow, F. P. C. Blamey, and K. S. Fischer: Effect of drought during early reproductive development on growth of cultivars of groundnut (Arachis hypogaed L.). Il. Biomass production, pod development and yield. Field Crops Res. 32: 211 225 (1993b).

Chapman. S. C., M. M. Ludlow, F. P. C. Blamey. and K. S. Fischer: Effects of drought during pod filling on utilization of water and on growth of cultivars of groundnut (Arachis hypogaea L.). Field Crops Res. 32: 243-255 (1993c).

Chauhan, Y. S., N. Venkatratnam, and A. R. Sheldrake: Factors affecting growth and yield 
of short-duration pigeonpea and its potential for multiple harvests. J. Agric. Sci. (Camb.). 109: 519-529 (1987).

Chauhan, Y. S.: Pigeonpea. In: Rooting Pattern of Tropical (rops. (pp. 79-91), Salam, A and W. A. Wahid. Eds.. McGraw Hill, India (199.3).

Ciha, A. J. and W. A. Brun: Stomatal size and frequency in soybeans. Crop Sci. 15: 309313 (1975).

Clarke, J. M., T. F. Townley-Smith, T. N. McCaig, and D. G. Green: Growth analysis of spring wheat cultivars of varying drought resistance. Crop Sci. 24: 537-541 (1984).

Clarke. J. M.. S. Romagosa, S. Jana, J. P. Srivastava, and T. N. McCaig: Relationship of excised leaf water loss rate and yield of durum wheat in diverse environments. Can. J. Plant Sici 69: 1075-1081 (1989).

Condon, A. G., R. A. Richards, and G. D. Farquhar: Carbon isotope discrimination is positively correlated with grain yield and dry matter production in field grown wheat. Crop Sici. 27: 996-100)! (1987).

Constable, G. A. and A. B. Hearn: Agronomic and physiological responses of soybean and sorghum crops to water deficits. I. Growth. development and yield. Aust. J. Plant Phisiol. 5: $159-167$ (1978).

Cortes, P. M. and T. R. Sinclair: Water relations of field grown soybean under drought. Crop Sci. 26: 99.3-998 (1986).

Cortes, P. M. and T. R. Sinclair: Osmotic potential and starch accumulation in leaves of field-grown soybean. Crop Sci. 27: 8()-84 (1987).

Cram. W. J.: Chloride accumulation as a homeostatic system: set points and perturbations. J. Exp. Bot. 34: 1484-1502 (198.3).

Cure, J. D.. C. D. Raper, J. R. P. Patterson, and W. P. Robarge: Dinitrogen fixation in soybean in response to leaf water stress and seed growth rate. Crop Sci. 25: 52-58 (1985).
Davies, J. D., J. M. Bennett, S. L. Albrecht, and K. J. Boote: Water relations, nitrogenase and root development of three grain legumes in response to soil water deficits. Field Crops Res. 21: 215-226 (1989).

Djekoun, A. and C. Planchon: Water status effect on dinitrogen fixation and photosynthesis in soybean. Agron. J. 83: 316-322 (1991).

Donald, C. M.: The breeding of crop ideotypes. Euphytica. 17: 385-403 (1968).

Doorenbos, J. and W. O. Pruitt: Guidelines for predicting crop water requirements. FAO $\mathrm{lr}$. rigation and Drainage paper no. 24, FAO. Rome, Italy (1975).

Duncan. W. G.: Leaf angle. leaf area, and canopy photosynthesis. Crop Sci. 11: $482-485$ (197I).

Duncan, W. G.. D. E. McCloud, R. McGraw, and K. J. Bonte: Physiological aspects of peanut yield improvement. (rop Sci. 18: 1015-1(2) (1978).

Eberhart, S. A. and W. A. Russell: Stability parameters for comparing varieties. Crop Sci. 6: $36-40(1966)$.

Ehdaie. B. and J. G. Waines: Yield potential and stress susceptibility of durum landraces in nonstress and stress environments. In: Proc: 7th Int. Wheat Genetic Symp.. (pp. 811815). Miller. T. E. and R. M. D. Koebner. Eds.. Cambridge. U.K. (1988).

Ehdaie, B., J. G. Waines, and A. E. Hall: Differential responses of landrace and improved spring wheat genotypes to stress environments. Crop Sci. 28: 838-842 (1988).

Ehdaie, B., A. E. Hall, G. D. Farquhar, H. T. Nguyen. and J. G. Waines: Water-use efficiency and carbon isotope discrimination in wheat. Crop Sci. 31: 1282-1288 (1991).

Ehleringer, J.: Leaf morphology and reflectance in relation to water and temperature stress. In: Adaptation of Plants to Water and High Temperature Stress. (pp. 295-308), Turner, 
N. C. and P. J. Kramer. Eds.. Wiley. New York (1980).

Ekanayaka. I. J.. J. C. O'Toole, D. P. Garrity, and T. M. Masajo: Inheritance of root characteristics and their relations to drought resistance in rice. Crop Sci. 25: 927-93.3 (1985).

Engin. M. and J. I. Sprent: Effects of water stress on growth and nitrogen fixing activity of Trifolium repe'ns. New Phytol. 72: 117-126 (1973).

Erickson. P. I. and D. L. Ketring: Evaluation of peanut genotypes for resistance to water stress in situ. (rop Sci. 25: 870)-876(1985).

Eze, J. M. O.. E. B. Dumbroff, and J. E. Thompson: Effects of temperature and moisture stress on the accumulation of abscisic acid in bean. Phrsiol. Plant. 58: 179-18.3 (198.3).

Fader, G. M. and H. R. Koller: Seed growth rate and carbohydrate pool sizes of the soybean fruit. Plamt Phisiol. 79: 66.3-666 (1985).

FAO (Food and Agricultural Organization of the United Nations ): FAO Production Yearbosk. 1991. Vol. 45. FAO, Rome. Italy (1992).

Farquhar, G. D. M. H. O'Leary, and J. A. Berry: On the relationship between carbon isotope discrimination and the intercellular carbon dioxide concentration in leaves. Aust. J. Plant Phisiol. 8: 121-137 (1982).

Farquhar, G. D. and R. A. Richards: Isotopic composition of plant carbon correlates with water use efficiency of wheat genotypes. Aust. J. Plant Phwsiol. 11: 539--552 (1984).

Farquhar, G. D., K. T. Hubick, I. Tereshima, A. G. Condon, and R. A. Richards: Genetic variation in the relationship between photosynthetic $\mathrm{CO}_{2}$ assimilation and stomatal conductance to water stress. In: Progress in Photosynthesis IV. (pp. 209-212), Biggins, J., Ed., Martinus Nijhoff, Dordrecht, The Netherlands ( 1987).

Farquhar, G. D., J. R. Ehleringer, and K. T. Hubick: Carbon isotope discrimination and photosynthesis. Annu. Rer. Plant Phỵsiol. 40: $5(03-5,37$ (1989).

Fereres, E., C. Gimenez, and J. M. Fernandez: Genetic variability in sunflower cultivars under drought. I. Yield relationships. Aust. J. Agric: Res. 37: 57.3-582 (1986).

Finlay. K. W. and G. N. Wilkinson: The analysis of adaptation in a plant hreeding progranme. Aust. J. Agric: Re's. 14: 742-7.54 (196.3).

Fischer, R. A. and N. C. Turner: Plant productivity in the arid and semi-arid zones. Amm! Re': Plamt Phisiol. 29: 277-317 (1978).

Fischer. R. A. and R. Maurer: Drought resistance in spring wheat cultivars. I. Cirain yield responses. Aust. J. Agric. Re's. 29: 897-912 (1978).

Fischer, R. A.: Growth and water limitation to dryland wheat yicld in Australia: A physiological framework. J. Aust. Inst. Agric. Scit. 45: 83-94 (1979).

Fischer, R. A.: Optimizing the use of water and nilrogen through breeding of crops. Plam Soril. 58: 249-278 (1981).

Fïscher, K. S., E. C. Johnson, and G. O. Edmeades: Breeding and selection for drought resistance in tropicai maize. In: Drought Resistance' in ('rops with Emphasis on Rice. (pp. 377-399), IRRI, Philippines (1982).

Fischer, M. J. and M. M. Ludlow: Adaptation to water deficits in Stylosanthus. In: The Biology and Agronomy of Stylosanthus. (pp. 16.3178), Stace, H. M. and L. A. Edye, Eds., Academic Press, Sydney (1984).

Flower, D. J.: The Role of Osmotic Adjustment in the Water Stressed Leaves of Pigeonpea (Cajanus cajan L. Millsp.). Ph.D. thesis, University of Queensland, Queensland (1985).

Flower, D. J. and M. M. Ludlow: Contribution of osmotic adjustment to the dehydration tolerance of water stressed pigeonpea (Cajanus cajan L. Millsp.) leaves. Plant Cell Environ. 9: 33-40 (1986). 
Flower, D. J. and M. M. Ludlow: Variations among accessions of pigeonpea (Cajanus (ajan L. Millsp.) in osmotic adjustment and dehydration wolerance of leaves. Field Crops Res. 17: 229-243 (1987).

Forseth, 1. N. and A. H. Teramura: Leaf energy hudget and calculated transpiration: the influence of leaflet orientation. Ecolog: 67: 564-571 (1986).

Gaff, D. F.: Protoplasmic tolerance of extreme water stress. In: Adaptation of Plants to Water and High Temperature Stress. (pp. 2(17-230). Turner, N. C. and P. J. Kramer. Eds., Wiley, New York (1980)).

Garay, A. F. and W. W. Wilhelm: Root system characteristics of two soybean isolines undergoing stress conditions. Agron. J. 75: 97.3977 (1983).

Garrity, D. P., C. Y. Sullivan, and W. M. Ross: Alternative approaches to improving grain sorghum productivity under drought stress. In: I)rought Resistance in Crops With Emphasis on Rice. (pp. 339-356), IRRI, Philippines (1982).

Gates, D. M.: Transpiration and leaf temperature. Amnu. Rev. Plant Phwsiol. 19: 211-238 (1968).

Girma, F. S. and D. R. Krieg: Osmotic adjustment in sorghum. I. Mechanisms of diurnal osmotic potential changes. Plant Physiol. 99: 577-582 (1992).

Gorham. J.. R. G. Wyn Jones, and E. M. McDonnell: Some mechanisms of salt tolerance in crop plants. Plant Soil. 89: 15-40 (1985).

Graham. P. H.: Stress tolerance in Rhizobium and Bradyrhizobium. and nodulation under adverse soil conditions. Can. J. Microbiol. 38: $475-484$ (1992).

Greacen. E. L. and J. S. Oh: Physics of root growth. Nature New Biol. 235: 24-35 (1972).

Greenberg. D. C.. J. H. Williams, and B. J. Ndunguru.: Differences in yield determin- ing processes of groundnut (Arachis hypogaea L.) genotypes in varied drought environments. Ann. Appl. Biol. 120: 557566 (1992).

Gregory, P. J.: Root growth of chickpea. fababean. lentil. and pea and effects of water and salt stress. In: World Crops: Cool Se'ason Food Legumes. (pp. 857-867), Summerfield, R. J.. Ed.. Kluwer Academic Publishers. London. U.K. (1988).

Grumet. R.. R. S. Albrechtsen. and A. D. Hanson: Growth and yield of barley isopopulations differing in solute potential. Crop Sci. 27: 991-995 (1987).

Giulman. S. L. and N. C. Turner: Differences in root and shoot development of tomato (L.ycopersicon esculentum $\mathrm{L}$.) varieties across contrasting soil environments. Plant Soril. 49: $127-136$ (1978).

Gupta. U. S.: Crop Improvement: Vol. I. Physiological Attributes. ()xford \& IBH Publishing Co. Pvt. L.td.. New Delhi, India (1992).

Hall, A. E., K. W. Foster, and J. G. Waines: Crop adaptation to semi-arid environments. In: Agriculture in Semi-Arid Environme'nts. (pp. 148-179). Cannell. G. H., A. E. Hall. and H. Lawton. Eds., Springer-Verlag. New York (1978).

Hall, A. E. and D. A. Grantz: Drought resistance of cowpea improved by selecting for early appearance of mature pods. Crop Sci. 21: $461-46+(1981)$.

Hall. A. E. and P. N. Patel: Breeding for resistance to drought and heat. In: Coupea Research. Production. and Utilization. (pp. 137-151). Singh. S. R. and K. O. Rachie. Eds.. Wiley, U.K. (1985).

Hall, A. E., R. G. Mutters. K. T. Hubick. and G. D. Farquhar: Genotypic differences in carbon isotope discrimination by cowpea under wet and dry field conditions. Crop Sci. 30: 300-305 (1990).

Hall, A. E., R. G. Mutters, and G. D. Farquhar: Genotypic and drought induced differences 
in carbon isotope discrimination and gas exchange of cowpea. Crop Sci. 32: 1-6(1992).

Hall. A. J.. C. Chimenti, N. Trapani. F. Vilella. and $R$. Cohen de Hunau: Yield in waterstressed maize genotypes: Asscciation with traits measured in seedlings and in flowering plants. Field Crops Res. 9: $41-57$ (1984).

Hamdi, Y. A.: Soil water tension and the movement of rhizobia. Soil Biol. Bioche'm. 3: 121126 (1970).

Hanks, J. R.. J. Keller, V. P. Ralsmusson. and G. D. Wilson: Line source sprinkler for conlinuous variable irrigation: crop production studies. Soil Sci. Soc. Am. Proc 40: 426+29 (1976).

Hanway, J. J. and C, R. Weber: N, P and K percentages in soybean (cilycine max $L$. Merrill.) plant parts. Agrem. J. 63: 286-290) (1971).

Hardwick, R. C.: Critical physiological traits in pulse crops. In: World Crops: Cool Seasom Food Le'gumes.s (pp. 885-896). Summerfield. R. J.. Ed., Kluwer Academic Publishers. Dordrecht, The Netherlands (1988).

Harrigan. E. S. and H. D. Barrs: Center for lirigation Research. 1983-84 report. (pp. 115118), CSIRO. Griffith. NSW, Australia (1984).

Harris, D.. R. B. Matthews, R. C. Nageswara Rao, and J. H. Williams: The physiological basis for yield differences between four genotypes of groundnut (Arachis hypogaca) in response to drought. III. Developmental processes. Exp. Agric. 24: 215-226 (1988).

Hartung. W. and W. J. Davies: Drought-induced changes in physiology and ABA. J. Exp. Bot. 42: 9 (1991).

Hoogenboom, G., C. M. Peterson, and M. G. Huck: Shoot growth rate of soybean as affected by drought stress. Agron. J. 79: 598607 (1987).

Hoogenboom, G., J. W. Jones, and J. W. White: Use of models in studies of drought toler- ance. In: Research on Drought Tolerance in Common Bean. (pp. 192-230). White. J. W.. G. Hoogenboom. F. Ibarra. and S. P. Singh, Eds.. CIAT. Colombia (1988).

Hoshikawa. K.: Significance of legume crops in improving the productivity and stability of cropping systems. In: Phospherus Nutrition of Cirain Legumes in the Semi-Arid Tropics. (pp. 173-181). Johansen. C.. K. K. Lee, and K. L. Sahrawat. Eds., International Crops Research Institute for the Semi-Arid Tropics. Patancheru, India (1991).

Hsiao, T. C. and E. Acevedo: Plant responses to water deficits, water-use efficiency, and drought resistance. Agric: Meteorol. 14: 59$84(1974)$.

Hsiac, T. C., F. Acevedo, E. Fereres, and D. W. Henderson: Stress metabolism, water stress. growth and osmotic adjustment. Philos. Trans. R. Soc: Londom B. 273: 479-50) (1976).

Hsiao, T. C.: The soil plant atmosphere continuum in relation to drought and crop production. In: Drought Resistance in Creps With Emplasis on Rice. (pp. 39-52), IRRI. Philippines (1982).

Hsiao, T. C., J. C. O'Toole. E. B. Yambao, and N. C. Turner: Influence of osmotic adjustment on leaf rolling and tissue death in rice (Oryza sativa L.). Plant Physiol. 75: 338341 (1984).

Hubick, K. T., G. D. Farquhar, and R. Shorter: Correlation between water-use efficiency and carbon isotope discrimination in diverse peanut (Arachis) germplasm. Aust. I. Plant Physiol. 13: 803-816 (1986).

Hubick, K. T., R. Shorter, and G. D. Farquhar: Heritability and genotype $¥$ environment interactions of carbon isotope discrimination and transpiration efficiency in peanut (Ara(his hypogaea L.). Aust. J. Plant Physiol. 15: 799-813 (1988).

Hume, D. J. and J. G. Criswell: Distribution and utilization of ${ }^{14} \mathrm{C}$-labelled assimilates in soybeans. Crop Sci. 13: 519-524 (1973). 
Hunt, L. A.: Designing improved plant types: a breeder's viewpoint. In: Systems Approaches for Sustainable Agricultural Development. (pp. 3-17), Penning de Vries, F. W. T.. P. Tang, and K. Metselaar, Eds., Kluwer Academic Publishers, Dordrecht. The Netherlands (1993).

Hurd, E. A.. T. F. Townley-Smith, L. A. Patterson. and C. H. Owen: Techniques used in producing Wascana wheat. Can. J. Plant Sici. 52: 689-691 (1972).

Hurd, E. A., T. F. Townley-Smith, D. Mallough, and L. A. Patterson: Wakooma durum wheat. Can. J. Plant Sci. 53: 261-262 (1973).

Hurd, E. A.: Phenotype and drought tolerance in wheat. Agric: Meteorol. 14: 39-55 (1974).

ICARDA (International Centre for Agricultural Research in Dry Areas): In: Annual Report. 1983. (pp. 154-155), ICARDA, Aleppo, Syria (1984).

ICARDA: In: Anmual Report. 1987. (pp. 196201), ICARDA, Aleppo, Syria (1985).

ICRISAT (International Crops Research Institute for the Semi-Arid Tropics): Annual Report, 1989. ICRISAT, Patancheru. India (1990).

ICRISAT: Annual Report. 1990). ICRISAT. Patancheru. India (1991).

ICRISAT: Mcdium Term Plam. Vol. I. ICRISAT. Patancheru. India (1992).

Jarvis, P. G. and K. G. McNaughton: Stomatal control of transpiration: Scaling up from leaf to region. Ads. Ecol. Re's. 15: $1-49$ (1986).

Jefferson. P. G.. D. A. Johnson. M. D. Runbaugh, and K. H. Asay: Water stress and genotypic effects on epicuticular wax production of alfalfa and crested wheat grass in relation to yield and excised leaf water loss rate. Can. J. Plant Sci. 69: 481-490 (1989).

Johansen. C.. Y. S. Chauhan. S. C. Gupta. and F. M. Taylan: Assessing short-duration pigeonpea for multiple-harvest potential. Int. Pigeonpea Nen'sl. No. 13: 15-17 (1991).
Johansen, C., B. Baldev, J. B. Brouwer, W. Erskine, W. A. Jermyn, L. J. Lang. B. A. Malik, A. A. Miah, and S. N. Silim: Biotic and abiotic stresses constraining productivity of cool season food legumes in Asia. Africa and Oceania. In: Expanding the Production and Use of Cool Season Food Le. gumes. (pp.175-194). Muehlbauer. F. J. and W. J. Kaiser, Eds., Kluwer. Academic Publishers, Dordrecht. The Netherlands (1994).

Johnson. D. A., M. D. Rumbaugh. and K. H. Asay: Plant improvement for semi-arid rangelands: possibilities for drought resistance and nitrogen fixation. Plant Soil. 58: 279-303 (1981).

Johnson, D. A.. R. A. Richards, and N. C. Turner: Yield, water relations, gas exchange, and surface reflectances of near-isogenic wheat lines differing in glaucousness. Crop Sci. 23: $318-325$ (1983).

Johnson. S. S. and J. L. Geadelnann: Influence of water stress on grain yield response to recurrent selection in maize. (rop $S_{c} i$. 29: $558-565$ ( 1989$)$.

Johnson, D. A., K. H. Assay, L. L. Tieszen, J. R. Ehleringer, and P. G. Jefferson: Carbon isotope discrimination: Potential in screening cool-season grasses for water limited environments. Crop Sci. 30: 338-343 (1990).

Jones, H. G.: Stomatal behavior and breeding for drought resistance. In: Stress Physiology in Crop Plants. (pp. 408-427), Mussell, H. and R. C. Staples, Eds.. Wiley. New York (1979).

Jones. H. G.: Interaction and integration of adaptive responses to water stress: The implications of an unpredictable environment. In: Stress Physiology in Crop Plants. (pp. 408428). Mussell, H. and R. C. Staples, Eds.. Wiley, New York (1980).

Jones. J. W. and B. Zur: Simulation of possible adaptive mechanisms in crops subjected to water stress. Irrig. Sci. 5: 251-264 (1984).

Jones, H. G. and J. E. Corlett: Current topics in drought physiology. J. Agric. Sci. (Camb.). 119: 291-296 (1992). 
Jordan, W. R., F. R. Miller, and D. E. Morris: Genetic variation in root and shoot growth of sorghum in hydroponics. Crop Sci. 19: $468-472$ (1979).

Jordan. W. R. and F. R. Miller: Genetic variability in sorghum root systems: implications for drought tolerance. In: Adaptation of Plants to Water and High Temperature Stress. (pp. 383-399). Turner, N. C. and P. J. Kramer, Eds.. Wiley, New York (1980).

Jordan. W. R., W. A. Dugas, and P. J. Shouse: Strategies for crop improvement for drought prone regions. Agric. Water Manage. 7: 281299 (198.3).

Kang. C. W., G. C. Kuo, and E. R. Son: Studies on drought tolerance screening method in mungbean. I. Drought tolerance of seedling stage in greenhouse. Res. Rep. Rural Des: Admin. 27: 191-198 (1985).

Kaspar, T. C., C. D. Stanley, and H. M. Taylor: Soybean root growth during the reproductive stages of development. Agrom. J. 70: 1105-1107 (1978).

Kaspar. T. C., H. M. Taylor, and R. M. Shibles: Tap root elongation rates of soybean cultivars in the glasshouse and their relation to field rooting depth. Crop Sici. 24: 916-920 (1984).

Ketring. D. L.: Root diversity among peanut genotypes. Crop Sci. 24: 229-2.32 (1984).

Ketring. D. L.: Physiological response of groundnut to temperature and water deficits breeding implications. In: Agrometeorolog: of Groundnut. (pp. 1.35-143), Sivakumar. M. V. K. and S. M. Virmani, Eds., ICRISAT, Patancheru, India (1986).

Khalfaoui, J. L. B. and M. Havard: Screening peanut cultivars in the field for root growth: a test by herbicide injection in the soil. Field Crops Res. 32: 173-179 (1993).

Kirchhoff. W. R., A. E. Hall, and W. W. Thomson: Gas exchange, carbon isotope discrimination and chloroplast ultrastructure of a chlorophyll deficient mutant of cowpea. Crop Sci. 29: 109-115 (1989).

Kramer. P. J.: The role of physiology in crop improvement. In: Linking Research to (rop Production. (pp. 51-62), Staples, R. C. and R. J. Kuhr, Eds.. Plenum Press. New York (1980).

Krishnamani, M. R. S.. J. H. Yopp, and (). Myers. Jr.: Leat solute leakage as a drought tolerance indicator in soybean. Phyton Argentina. 44: 43-49 (1984).

Kuhad. M. S.. A. S. Nandwal, I. S. Sheoran, and K. D. Sharma: Water relations, carbon exchange and nitrogenase in chickpea under soil water deprivation. Ann. Arid Zome. 31: $309-310(1992)$.

Lawn, R. J. and W. A. Brun: Symbiotic nitrogen fixation in soybeans. I. Effects of photosynthetic source-sink manipulations. Crop Sci. 14: $11-16(1974)$.

Lawn, R. J.: Responses of four grain legumes to water stress in south eastern Queensland. I. Physiological response mechanisms. Aust. J. Agric. Res. 33: 481-496 (1982a).

Lawn, R. J.: Responses of four grain legumes to water stress in south eastern Queensland. 11. Plant growth and soil water extraction patterns. Aust. J. Agric. Res. 33: 497-509 (1982b).

Lawn, R. J.: Responses of four grain legumes to water stress in south eastern Queensland. III. Dry matter production, yield and water use efficiency. Aust. J. Agric. Res. 33: 511521 (1982c).

Lawn, R. J.: Agronomic and physiological constraints to the productivity of tropical grain legumes and prospects for improvement. Exp. Agric: 25: 509-528 (1989).

Lawn, R. J. and B. C. Imrie: Crop improvement for tropical and subtropical Australia: designing plants for different climates. Field Crops Res. 26: 113-139 (1991). 
Legumes Program. Annual Report. 199/. (pp. 17-21). International Crops Research Institute for the Semi-Arid Tropics, Patancheru. India (1992).

Leopold, A. C., M. E. Musgrave, and K. M. Williams: Solute leakage resulting from leaf desiccation. Plant Physiol. 68: 1222-1225 (1981).

Levitt, J.: Responses of Plants to Environmental Stresses. Vol. II. Water, Radiation, Salt and other Stresses. 2nd ed.. Academic Press, New York (1980).

Looker, C. H.: Studies of the Growth and Development of Roots in Vicia faba L.. Ph.D. thesis, Universily of Nottingham, U.K. (1978).

Lope\%, F. B.. T. L. Setter, and C. R. McDavid: Carbon dioxide and light responses of photosynthesis in cowpea and pigeonpea during water deficit and recovery. Plam Physiol. 85: 990-995 (1987).

Ludlow, M. M.: Stress physiology of tropical pasture plants. Trop. Grasslands 14: 1.36$145(198() \mathrm{a})$.

Ludlow, M. M.: Adaptive significance of stomatal responses to watter stress. In: Adaptarion of Plants to Water and High Temperature Stress. (pp. 123-138), Turner, N. C. and Kramer. P. J., Eds., Wiley. New York (1980).

Ludlow. M. M. and O. Bjorkman: Paraheliotropic leaf movement in Siratro as a protective mechanism against drought induced damage to primary pholosynthetic reactions: damage by excessive light and heat. Planta. 161: 505-518 (1984).

Ludlow, M. M.. M. J. Fischer, and J. R. Wilson: Stomatal adjustment to water deficits in three tropical grasses and a tropical legume grown in controlled conditions and in the field. Aust. J. Plant Phisiol. 12: 131-149 (1985).

Ludlow. M. M.: Contribution of osmotic adjustment to the maintenance of photosynthesis during water stress. In: Progress in Photosynthesis Research. Vol. 4. (pp. 161-168). Biggins. J., Ed., Martinus Nijhoff, Dordrecht. The Netherlands (1987).

Ludlow, M. M. and R. C. Muchow: A critical evaluation of traits for improving crop yields in water-limited environments. Ads: Agron. 43: $107-153$ (1990).

Ludlow, M. M., J. Basnayake, M. Cooper, Y. Tao, J. Manners, R. Henzell, S. Duncan. and 1. Godwin: Osmotic adjustment to water stress in grain sorghum: Inheritance and linkage analysis. In: Proc. Molecular Markers in Sorghum and Pearl Millet for Developing Comtries. University of East Anglia, Norwich, U.K. (1993).

Malhotra, R. S. and K. B. Singh: Classification of chickpea growing environments to control genotype by environment interaction. Euphricica. 58: 5-12 (1991).

Mansfield, T. A. and W. J. Davies: Abscisic acid and water stres. Biochem. Sor: Trans. 11: $557-560(198.3)$.

Markhan, A. H.: Comparative water relations of Phaseolus vulgaris L. and Phaseolus acutifolius grav: Plant Physiol. 77: 11.3-117 (1985).

Marshall, D. R.: Alternative approaches and perspectives in breeding for higher yields. Ficld Crops Res. 26: 171-190 (1991).

Martin. B., J. Neinhuis, G. King. and A. Schaefer: Restriction fragment length polymorphisms associated with water use efficiency in tomato. Science. 243: 1725-1728 (1989).

Mathew's. R. B.. D. Harris, R. C. Nageswara Rao, J. H. Williams, and K. D. R. Wadia: The physiological basis for yield differences between four genotypes of groundnut (Arachis hypogaea) in response to drought. I. Dry matter production and water use. Exp. Agric. 24: 191-202 (1988a).

Mathews, R. B., D. Harris, J. H. Williams, and R. C. Nageswara Rao: The physiological 
basis for yield differences between four genotypes of groundnut (Arachis hypogaea) in response to drought. II. Solar radiation interception and leaf movement. Exp. Agric. 24: 203-213 (1988h).

McBlain. B. A. and D. J. Hume: Physiological studies of higher yield in new early maturing soybean cultivars. Can. J. Plant Sici. 60: 1315-1326 (1980).

Meckel. L.. D. B. Egli, R. E. Phillips. D. Redeliffe, and J. E. Leggett: Effect of moisture stress on seed grouth in soybcan. Agron. J. 76: $647-650(1984)$.

Mengel. D. B. and S. A. Barber: Development and distribution of the corn root system under field conditions. Agrom. J. 66: $3+1-3+34$ (1974).

Meterler Kamp. H. R. A.: Response to early planting and irrigation of a late maturing groundnut variety. Rhodesia Agric. J. 64: $127-1.30$ (1967).

Meyer. G. E.: Simulation of moisture stress effects on soybean yield components in Nebraska. Trans. Am. Soc. Agric. Eng. 28: 118 $128(1985)$.

Meyer. R. F. and J. S. Boyer: Osmoregulation. solute distribution. and growth in soybean seedlings having low water potentials. Planta 151: $482-489(1981)$.

Minguez, M. I.. B. Ruiz-Nogueira, and F. Sau: Faba bean productivity and optimum canopy development under a Mediterranean climate. Field Crops Res. 33: 435-447 (199.3).

Morgan. J. M.: Osmotic adjustment in the spikelets and leaves of wheat. J. Exp. Bot. 31: 655-665 (1980).

Morgan. J. M.: Osmoregulation as a selection criterion for drought tolerance in wheat. Aust. J. Agric. Res. 34: 607-614 (1983).

Morgan, J. M.: Osmoregulation and water stress in higher plants. Annu. Rev. Plant Physiol. 35: 299-319 (1984).
Morgan. J. M. and A. G. Condon: Water use, grain yield and osmoregulation in wheat. Aust. J. Plamt Physiol. 13: 523-5.32 (1986).

Morgan, J. M., R. A. Hare, and R. J. Fletcher: Genetic variation in osmoregulation in bread and durum wheats and its relationships to grain yield in a range of field environments. Aust. J. Agric: Res. 37: $4+9-457$ (1986).

Morgan, J. M.: Osmotic components and proportion associaled with genotypic differences in osmoregulation in wheat. Aust. I. Plamt Phisiol. 19: 67-76 (1992).

Muchow. R. C. and D. A. Charles-Edwards: An analysis of the growth of mung beans at a range of plant densities in tropical Australia. 1. Dry matter production. Aust. J. Agric. Re's. 33: $41-51$ (1982).

Muchow. R. C.: Phenology, seed yield and water use by grain legumes grown under different soil water regimes in a semi-arid environment. Ficld Crops Res. 11: 81-97 (1985ia).

Muchow, R. C.: ('anopy development in grain legumes grown under different soil water regimes in a semi-arid tropical environment. Field Crop. Re's. 11: 99-109 (1985h).

Muchow, R. C.: Stomatal behavior in grain legumes grown under different soil water regimes in a semi-arid tropical environment. Ficld (rops Res. 11: 291-307 (1985c).

Muchow, R. C. and T. R. Sinclair: Water and nitrogen limitations in soybean grain production. II. Field and model analysis. Ficld Crops Res. 15: 14.3-156 (1986).

Muchow, R. C., G. L. Hammer, and P. S. Carberry: Optimizing crop and cultivar selection in response to climatic risk. In: $\mathrm{Cli}$ matic Risk in Crop Production: Models and Management for the Semi-Arid Tropics. (pp. 235-262), Muchow, R. C. and J. A. Bellamy, Eds., CAB International, Wallingford, U.K. (1991).

Muchow, R. C. and P. S. Carberry: Designing improved plant types for the semiarid trop- 
ics: agronomists' viewpoints. In: Systems Approaches for Sustainable Agricultural Development, (pp. 37-61), Penning de Vries, F. W. T., P Tang, and K. Metselaar, Eds., Kluwer Academic Publishers, Dordrecht, The Netherlands (1993).

Mungomery, V. E., R. Shorter, and D. E. Byth: Genolype $¥$ environment interactions and environmental adaptation. 1. Pattern analysis application to soybean. Aust. J. Agric. Res. 25: 59-72 (1974).

Munns, R.: Why measure osmotic adjustment? Aust. J. Plant Physiol. 15: 717-726 (1988).

Nagarajarao, Y., S. Mallick, and (i. C. Singh: Moisture depletion and root growth of different varieties of chickpea under rainfed conditions. Ind. I. Agron. 25: 289-293 (1980).

Nageswara Rao, R. C., S. Singh, M. V. K. Sivakumar, K. L. Srivastava, and J. H. Williams: Effect of watcer deficit at different growth phases of peanut. I. Yield responses. Agrom. J. 77: 782-786 (1985a).

Nageswara Rilo, R. C., S. Singh, M. V. K. Sivakumar, K. L. Srivastava, and J. H. Williams: Effect of water deficit at different growth phases of peanut. II. Response to drought during preflowering phase. Agron. J. 80: $4.31-4.38$ (1986h).

Nageswara Rao, R. C., J. H. Williams, and M. Singh: Genotypic sensitivity to drought and yield potential of peanut. Agron. J. 81: 88789.3 (1989).

Nageswara Rao, R. C.: Some crop physiological approaches for groundnut improvement. J. Oilseeds Res. 9: 286-296 (1992).

Nageswara Rao, R. C., J. H. Williams, K. D. R. Wadia, K. T. Hubick, and G. D. Farquhar: Crop growth, water-use efficiency and carbon isotope discrimination in groundnut (Arachis hypogaea L.) genotypes under endof seuson drought conditions. Ann. Appl. Biol. 122: 357-367 (1993).
Nageswara Rao, R. C. and G. C. Wright: Stability of the relationship between specific leaf area and carbon isotope discrimination across environments in peanut. Crop Sci. 34(1): $98-103$ (1994).

Nam, N. H., Y. S. Chauhan, and C. Johansen: Comparison of extra-short-duration pigeonpea with short-season legumes under rainfed conditions on alfisols. Exp. Agric. 29: 307316 (1993).

Nutman. P. S.: Centenary lecture on nitrogen fixation. In: A Century of Nitrogen Fixation Research: Present Status and Future Prospects. (pp. 69-106). Bergersen. F. J. and J. R. Postgate. Eds.. The Royal Society. London, U.K. (1987).

Ojehmon, (). O.: Effect of continuous removal of open flowers on the seed yield of (wo varieties of cowpea. Vigna unguiculata $\mathrm{L}$. Walp. J. Agric. Sci. (Camb.). 74: 375-381 (1970).

Onim. J. F. M.: A isociation between grain yield and drought resistance in pigeonpea in marginal rainfall areas of Kenya. In: More Food from Better Technology: (pp. 864-872), Holmes, J. C. and W. M. Tahor, Eds., FAO. Rome, Italy (198.3).

Oosterhuis. D. M. and S. D. Wullschleger: Drought tolerance and osmotic adjustment of various crops in response to water stress. Ark. Furm Res. 37: 1 (1988).

O'Toole, J. C., R. S. Aquino, and K. Alluri: Seedling stage drought response in rice. Agron. J. 70: 1101-1103 (1978).

O'Toole, J. C. and T. T. Chang: Drought resistance in cereals: a case study. In: Stress Physiology in Crop Plants. (pp. 373-405). Mussell. H. and R. C. Stapies. Eds., Wiley, New York (1979).

O'Toole, J. C. and Soemartono: Evaluation of a simple technique for characterizing rice root systems in relation to drought resistance. Euphutica. 30: 283-290 (1981). 
Paje, M. C. M., M. M. Ludlow. and R. J. Lawn: Variation among soybean $(G / y c i n e$ max $\mathrm{L}$. Merr.) accessions in epidermal conductance of leaves. Aust. J. Agric: Res. 39: 363-373 (1988).

Pankhurst. C. E. and J. I. Sprent: Effects of water stress on the respiratory and nitrogen-fixing activity of soybean root nodules. J. Exp. Bot. 26: 287-304 (1975).

Parkhurst, D. F. and O. L. Loucks: Optimal leaf size in relation to environment. J. Ecol. 60: 505-5.37 (1972).

Parlevliet. J. E. and J. C. Zadocks: The integrated concept of disease resistance: A new view including horizontal and vertical resistance in plants. Euphytica. 26: 5-21 (1977).

Parsons, L. R. and T. K. Howe: Effects of water stress on the water relations of Phaseolus rulgaris and the drought resistant Phascolus acutifolius. Phisiol. Plant. 60: 197-202 (1984).

Passioura, J. B.: The effect of root geometry on the yield of wheat growing on stored water. Aust. J. Agric. Res. 23: 745-752 (1972).

Passioura, J. B.: Grain yield, harvest index and water use of wheat. J. Aust. Inst. Agric. Sci. 43: $117-121$ (1977).

Passioura, J. B.: The role of root system characteristics in the drought resistance of crop plants. In: Drought Resistance in Crops With Emphasis on Rice. (pp. 71-82), IRRI, Philippines (1982).

Passioura, J. B.: Roots and drought resistance. Agric. Water Manage. 7: 265-280 (1983).

Passioura, J. B.: Overview of the processes limiting crop production on duplex soils. Aust. J. Exp. Agric. 32: 987-990 (1992).

Paterson, A. H.: Agricultural genetics and DNA markers. Adv. Agron. 46: 40-90 (1991).

Pierce, M. and K. Raschke: Correlation between loss of turgor and accumulation of abscisic acid in detached leaves. Planta. 148: 174182 (1980).

Premachandra. G. S., H. Saneoka, and S. Ogata: Cell membrane stability, an indication of drought tolerance. as affected by applied nitrogen in soybean. J. Agric. Sci. (Camb.). 115: $63-66(1990)$.

Rachie, K. O. and L. M. Roberts: Grain legumes of the low-land tropics. Ads: Agron. 26: 11.32 (1974).

Rafalski. J. A.. S. V. Tingey, and J. G. K. Williams: RAPD markers - a new technology for genetic mapping and plant breeding. AgBiotech Ne's's Infor. 3: 645-648 (1991).

Rao. A. V. and B. Venkaleswarlu: Nitrogen fixaltion as influenced by water stress in selected crop legumes of the Indian arid zone. Arid Soil Res. Rehah. 1: 89-96 (1987).

Rasmusson, D. C.: A plant breeder's experience with ideotype breeding. Ficld (ropss Res. 26: $191-200)(1991)$.

Rawal, K. M.: Natural hybridization among wild, weedy and cultivated Vigna unguiculata L. Walp. Euphytica. 24: 699-707 (1975).

Rawson, H. M. A. K. Bagga, and P. M. Bremner: Aspects of adaptation by wheat and barley (o) soil moisture deficits. Aust. J. Plant Physiol. 4: 389-401 (1977).

Read, J. J., R. C. Johnson, B. F. Carver, and S. A. Quarrie: Carbon isotope discrimination, gas exchange, and yield of spring wheat selected for abscisic acid content. Crop Sci. 31: 139 146 (1991).

Reddy, M. S. and R. W. Willey: A study of pearl millet/groundnut intercropping with particular emphasis on the efficiencies of leaf canopy and rooting pattern. In: International Workshop on Intercropping. (pp. 202-209). Willey, R. W., Ed., International Crops Research Institute for the Semi-Arid Tropics, Patancheru, India (1981). 
Richards, R. A. and N. Thurling: Variation between and within species of rapeseed (Bras. sica (campestris and B. napus) in response to drought struss. II. Growth and development under natural drought stress. Aust. I. Agric. Re.s. 29: 479-490)(1978).

Richards, R. A. and J. B. Passioura: Seminal root morphology and water use of wheat. I. Environmental effects. Crop Sci. 21: 249-252 (198la).

Richards, R. A. and J. B. Passioura: Seminal root morphology and water use of wheat. II. Genetic variation. ('rop Sci. 21: 249-252 (198/b).

Richards, R. A., H. M. Rawson, and D. A. Johnson: Cilaucousness in wheat: Its development and effect on water use efficiency. gan exchange and photosynthetic tissue temperatures. Aust. I. Plant Physiol. 13: 46.547.3 (1986).

Ritchic, J. T.: A user-oriented model of the soil water balance in wheat. In: Whe'at cirowth and Modelling. (pp. 293-305). Day. W. and Atkin. R. K.. Eds.. Plenum Press. New York (1985).

Robertson. B. M., A. E. Hall, and K. W. Foster: A ficld technique for screening genotypic differences in root growth. Crop Sit. 25: 1(1)84-1(09) (1985)

Robertson. G. W.: Possibilities and linitations of rainfall analysis for predicting crop available water. In: Drought Research Priorities for the Dryland Tropics. (pp. 3-14). Bidinger. $F$. $R$, and $C$. Johansen. Eds.. ICRISAT. Patancheru, India (1988).

Rose. I. A., K. S. McWhirter, and R. A. Spurway: ldentification of drought tolerance in earlymaturing indeterminate soybeans (Glycine max L. Merr.). Aust. J. Agric. Res. 43: 645657 (1992).

Rosenberg. N. J.: North American Droughts. AAAS Selected Symposium. American Society of Agronomy, Madison, WI (1978).
Rosenow, D. T., J. E. Quisenberry, C. W. Wendt. and L. E. Clark: Drought tolerant sorghum and cotton germplasm. Agric. Water Manage. 7: 207-222 (1983).

Rosielle. A. A. and J. Hamblin: Theoretical aspects of selection for yield in stress and nonstress environments. Crop Sci. 21: 943-946 (1981).

Saeed. M. and C. A. Francis: Yield stability in relation to maturity in grain sorghum. Crop Sci. 23: 683-687 (1983).

Sall; K. and T. R. Sinclair: Soybean genotypic differences in sensitivity of symbiotic nitrogen fixation to soil dehydration. Plant Soil 133: $31-37$ (1991).

Samet. J. S.. P. M. Cortes, and T. R. Sinclair: Diurnal and seasonal changes in abscisic acid of field grown soybeans subjected to drought stress. Field Crops Res. 8: 49-59 (1984).

Santarius, K. A.: 4ssimilation of $\mathrm{CO}_{2}$. NADP. and $P G A$ reduction and $A T P$ synthesis in intact leaf cells in relation to water content. Planta. 73: 228-242 (1967).

Sato, H. and K. Gotoh: The phototropic movement and its varietal difference in the leaf of common bean (Phaseolus vulgaris L.). J. Hokkaido Uni1. Educ. Sect. 30: 45-51 (1979).

Saxena. N. P.: Chickpea. In: The Physiology of Tropical Field Crops. (pp. 419-452), Goldsworthy, P. R. and N. M. Fischer, Eds.. Wiley, New York (1984).

Saxena. N. P.: Screening for adaptation to drought: Case studies with chickpea and pigeonpea. In: Adaptation of Chickpea and Pigeonpea to Abiotic Stress. (pp. 63-76), Saxena. N. P. and C. Johansen, Eds., ICRISAT, Patancheru, India (1987).

Saxena. N. P., C. Johansen. M. C. Saxena, and S. N. Silim: Selection for drought and salinity tolerance in cool season food legumes. 
In: Breeding for Stress Tolerance in CoolSeason Food Legumes. (pp. 245-270)). Singh. K. B. and M. C. Saxena. Eds., Wiley, U.K. (1993).

Saxena. N. P.. L. Krishnamurthy, and C. Johansen: Registration of a drought resistant chickpea germplasm. (rop) Sci. 33: 1424 (1994).

Schnyder. H.: The role of carbohydrate storage and redistribution in the surce-sink relattions of wheat and barley during grain filling - a review. New Phrol. 123: 23.3-245 (1993).

Schwab. K. S. and U. Heher: Thylakoid membrane stability in drought tolerant and drought susceptible plants. Plamta. 161: 37-45 (1984).

Schwab, K. B. and D. F. Gaff: Sugar and ion content in leaf tissues of several drought tolerant plants under water stress. I. Plamt Phisiol. 125: 257-265 (1986).

Sedgley, R. H.: An appraisal of the Donald ideotype after 21 years. Field ('rops Res. 26: $93-112(1991)$.

Seif, E.. J. C. Evans, and L.. N. Balaam: A multivariate procedure for classifying environments according to their interaction with genotypes. Aust. J. Agric: Res. 30: 1021$1026(1979)$.

Seong. R. C., H. J. Chung. and E. H. Hong: Varietal responses of soybean germination and seedling elongation to temperature and polyethylene glycol solution. Korean J. Crop Sci. 33: 31-37 (1988).

Shackel, K. A. and A. E. Hall: Reversible leaf movements in relation to drought adaptation of cowpeas (Vigna unguiculata L. Walp.). Aust. J. Plant Physiol. 6: 265-276 (1979).

Shackel, K. A. and A. E. Hall: Comparison of water relations and osmotic adjustment in sorghum and cowpea under field conditions. Aust. J. Plant Phvsiol. 10: 423-435 (1983).
Sheoran, I. S., Y. P. Luthra, M. S. Kuhad, and R. Singh: Effects of water stress on some enzymes of nitrogen metabolism in pigeonpea. Phyreche'mistry 20: 2675-2677 (1981).

Sheldrake. A. R. and A. Narayanan: Growth. development and nutrient uptake in pigeonpeas (Cajanus cajan). J. Agric: Sci. (Camb.). 92: $51.3-526(1979)$.

Shorter. R. and R. O. Hammons: Pattern analysis of genotype adaptation and genotype $¥$ environment interactions in the uniform peanut performance tests. Pcamut Sci. 12: 3.5-41 (1985)

Shorter. R. ()., R. J. Lawn, and (i. L. Hammer: Improving genotypic adaptation in crops: a role for breeders, physiologists and modellers. Exp. Agric. 27: 155-175 (1991).

Silim. S. N.. M. C. Saxena, and W. Erskine: Adaptation of lentil to the Mediterranean environmenl. 1. Factors affecting yield under drought conditions. Exy). Agric. 29: 9-19 (1993).

Sinclair, T. R. and C. T. deWit: Photosynthate and nitrogen requirements for seed production hy various crops. Science. 189: 565$567(1975)$.

Sinclair, T. R.: Water and nitrogen limitations in soybean grain production. 1. Model development. Fie'd Crops Re's. 15: 125-141 (1986).

Sinclair, T. R. and M. M. Ludlow: Intluence of soil water supply on the plant water balance of four tropical grain legumes. Aust. J. Plant Physiol. 13: 329-341 (1986).

Sinclair. T. R., A. R. Zimet, and R. C. Muchow: Changes in soybean nodule number and dry weight in response to drought. Field Crops Res. 18: 197-202 (1988).

Singh, K. B.: Chickpea breeding. In: The Chickpea. (pp. 127-162), Saxena, M. C. and K. B. Singh, Eds., CABI, Wallingford, U.K. (1987).

Singh, M., R. C. N. Rao, and J. H. Williams: A statistical assessment of genotypic sensitiv- 
ity of groundnut (Arachis hypogaea L.) to drought in line source sprinkler experiments. Euphytica. 57: 19-25 (1991).

Singh. P.: Influence of water deficits on phenology, growth and dry matter allocation in chickpea (Cicer arietinum). Field Crops Res. 28: 1-15 (1991).

Singh, R. P. and G. Subba Reddy: Identifying crops and cropping systems with greater production stability in water deficit environments. In: Irought Research Priorities for the Dryland Tropics. (pp. 77-85), Bidinger. F. R. and C. Johansen, Eds., ICRISAT, Patancheru, India (1986).

Singh, S. P. and J. W. White: Breeding common beans for adaptation to drought conditions. In: Research on Drought Tolerance in Com. mon Bean. Documento de Trabajo No. 41. (pp. 261-285), White, J. W., F. Hoogenborm. F. Ibarra. and S. P. Singh. Eds.. Bean Program. CIAT. Cali, Colombia (1988).

Singh, T. N., L. G. Paleg, and D. Aspinall: Stress metabolism: I. Nitrogen metabolism and growth in the barley during water stress. Aust. I. Biol. Sici. 26: 45-56 (1973).

Smith, D. L.. M. Dijak. and D. J. Hume: The effect of water deficit on $\mathrm{N}_{2}\left(\mathrm{C}_{2} \mathrm{H}_{2}\right)$ fixation by white bean and soybean. Can. J. Plant Sci. 68: 957-967 (1988).

Soja, G., A. Soja. and R. Zarghami: Early screening of fababean (Vicia faba L.) for drought resistance. FABIS Ne'w'sl. 22: 20-24 (1988).

Sponchiado, B. N.. J. W. White, J. A. Castillo. and P. G. Jones: Root growth of common bean cultivars in relation to drought tolerance in environments with contrasting soil types. Exp. Agric. 25: 249-257 (1989).

Sprent, J. 1.: Effects of water stress on nitrogen fixation in root nodules. Plant Soil. Suppl.: 225-228 (1971).

Sprent, J. l.: Adherence of sand particles to soybean roots under water stress. New'Phytol. 74: $461-463$ (1975).
Sprent, J. I.: Water deficits and nitrogen fixing root nodules. In: Water Deficits and Plant Growth, Vol. IV. Soil Water Management, Plant Responses and Breeding for Drought Resistance. (pp. 291-313), Kozlowski, T. T., Ed., Academic Press, New York (1976).

Squire, G. R.: The Physiology of Tropical Crop Production. CAB International. U.K. (1990).

Steele, W. M.: Cowpeas. In: Evolution of Crop Plants. (pp. 183-185), Simmonds, N. W.. Ed., Longman, London (1976).

Steponkus, P. L., K. W. Shahan, and J. M. Cutler: Osmotic adjustment in rice. In: Drought Resistance in Crops with Emphasis on Rice. (pp. 181-194), IRRI. Philippines (1982).

Stirling. C. M.. C. R. Black. and C. K. Ong: The response of groundnut (Arachis hypogaea L.) to timing of irrigation. II. ${ }^{14} \mathrm{C}$ partitioning and plant water status. J. Exp. Bot. 40: 1.36.3-1.373 (1989)

Subbarao, G. V., C. Johansen. R. C. Nageswara Rao, and G. C. Wright: Transpiration efficiency - avenues for genetic improvement. In: Handhook of Plant and Crop Physiology: Pessarakli. M., Ed., Dekker, New York (.1994).

Summerfield. R. J. and H. C. Wien: Effects of photoperiod and air temperature on growth and yield of economic legumes. In: Advances in Legume Science. Vol. I. (pp. 17-36), Summerfield, R. J. and A. H. Bunting. Eds., Royal Botanic Gardens, Kew, U.K. (1980).

Summerfield, R. J., S. Shanmugasundaram, E. H. Roberts, and P. Hadley: Soybean adaptation to photothermal environments and implications for screening germplasm. In: Soybean in Tropical and Sub-Tropical Cropping System.s, (pp. 333-352), Shanmugasundaram, S. and E. W. Sulzberger, Eds., Asian Vegetable Research and Development Centre. Taiwan (1985).

Swaraj. K.: Environmental stress and symbiotic $\mathrm{N}_{2}$ fixation in legumes. Plant Physiol. Biochem. 14: 117-130 (1987). 
Tanksley, S. D., N. D. Young. A. H. Paterson. and $\mathrm{M}$. W. Bonierbale: RFLP mapping in plant breeding: new tools for an old science. Biotechnology: 7: 257-264 (1989).

Tanner, C. B. and T. R. Sinclair: Efficient water use in crop production: Research or re-search. In: Limitations to Efficient Water (/se in Crop Production. (pp. 1-28). Taylor. H. M.. W. R. Jordan, and T. R. Sinclair. Eds. American Society of Agronomy, Madison. WI (1983).

Tanzarella, O. A., C. dePace, and A. Filippetti: Stomatal frequency and size in Vicia faba $\mathrm{L}$. Crop Sci. 24: 1070-1076 (1984).

Taylor, H. M. and E. W. Carson: The Plant Root and Its Environment. University of Virginia Press, Charlottesville, VA (1974).

Tıetz. A., M. Ludehig. M. Dingkuhn, and K. Dorffing: Effect of abscisic acid on the transport of assimilates in barley. Planta. 152: $557-561$ ( 1981$)$.

Turk, K. J. and A. E. Hall: Drought adaptation of cowpea. Il. Influence of drought on water use and relations with growth and seed yield. Agron. J. 72: 428-433 (1980a).

Turk, K. J. and A. E. Hall: Drought adaptation of cowpea. III. Influence of drought on water use and relations with growth and seed yield. Agron. J. 72: 434-439 (1980b).

Turner, N. C. and J. E. Begg: Response of pasture plants to water deficits. In: Plant Relations in Pastures. (pp. 50-66), Wilson, J. R. Ed.. CSIRO, Melbourne, Australia (1977).

Turner, N. C.: Drought resistance and adaptation to water deficits in crop plants. In: Stress Physiology in Crop Plants. (pp. 343-372), Mussell, H. and R. C. Staples, Eds., Wiley, New York (1979).

Turner, N. C. and M. M. Jones: Turgor maintenance by osmotic adjustment: $\mathrm{A}$ review and evaluation. In: Adaptations of Plants to Water and High Temperature Stress. (pp. 87-103), Turner, N. C. and P. J. Kramer. Eds., Wiley, New York (1980).
Tumer. N. C.: The role of shoot characteristics in drought resistance of crop plants. In: Drought Resistance in Crops with Emphasis on Rice. (pp. 115-134), IRR1, Philippines (1982).

Turner, N. C.. E. D. Schulze, and T. Gollan: The responses of stomata and leaf gas exchange to vapor pressure deficits and soil water content. I. Species comparisons at high soil water contents. Oecologia. 63: 3.38-342 (1984).

Turner, N. C.: Adaptations to water deficits: a changing perspective. Aust. J. Plant Physiol. 13: $175-190$ (1986a).

Turner, N. C.: Crop water deficits: a decade of progress. Ads: Agrom. 39: 1-51 (1986b).

Turner, N. C., W. R. Stern, and P. Evans: Water relations and osmotic adjustment of leaves and roots of lupins in response to water deficits. Crop Sci. 27: 977-983 (1987).

Venkateswarlu, B., N. Saharan, and M. Maheswari: Nodulation and $\mathrm{N}_{2}$ fixation in cowpea and groundnut during water stress and recovery. Field (rops Res. 25: 22.3-232 (1990).

Virgona, J. M.. K. T. Hubick, H. M. Rawson. G. D. Farquhar, and R. W. Dowlies: Genotypic variation in transpiration efficiency, carbon isotope discrimination and carbon allocation during early growth in sunflower. Aust. J. Plant Physiol. 17: 207-214 (1990).

Virmani, S. M. and P. Singh: Agroclimatological characteristics of the groundnut growing regions in the semi-arid tropics. In: Agrometeorology of Groundnut. (pp. 35-46), Sivakumar, M. V. K. and S. M. Virmani, Eds., ICRISAT, Patancheru, India (1986).

Walker, D. W. and J. C. Miller, Jr.: Rate of water loss from detached leaves of drought resistant and susceptible genotypes of cowpea. Hortic. Sci. 21: 131-132 (1986).

Wallace, D. H., J. P. Baudoin, J. Beaver, D. P. Coyne, D. E. Halseth, P. N. Masaya, H. M. Munger, J. R. Myers, M. Silbernagel, K. S. 
Yourstone, and R. W. Zobel: Improving efficiency of breeding for higher crop yield. Theor. Appl. Genet. 86: 27-40 (1993).

Weaver, D. B., D. L. Thurlow, and R. M. Patterson: Stability parameters of soybean cultivars in maturity groups VI, VII, and VIII. Crop Sci. 23: 569-571 (1983).

Westgate, M. E., J. R. Schussler, D. C. Reicosky, and M. L. Brenner: Effects of water deficits on seed development in soybeans. II. Conservation of seed growth rate. Plant Physiol. 91: 980-985 (1989).

White, J. W.: Preliminary results of the bean international drought yield trial (BIDYT). In: Research on Drought Tolerance in Common Bean. (pp. 126-145), White. J. W.. G. Hoogenboom, F. Ibarra, and S. P. Singh. Eds.. CIAT. Cali, Colombia (1988).

White, J. W. and J. A. Castillo: Studies at CIAT on mechanisms of drought tolerance in beans. In: Re'search on Drought Tolerance' in ('ommon Bean. (pp. 146-151). White, J. W.. G. Hoogenboom. F. Iharra, and S. P. Singh. Eds.. CIAT. Cali. Colombia (1988).

White, J. W.. J. A. Castillo, and J. Ehleringer: Associations between productivity, root growth and carbon isotope discrimination in Phascolus v'ulgaris under water deficit. Aust. J. Plant Physiol. 17: 189-198 (1990).

Wiebe. H. H.: Morphological adaptations to water stress. In: Adaptations of Plants to Water and High Temperature Stress. (pp. 439-443). Turner. N. C. and P. J. Kramer. Eds., Wiley. New York (1980).

Wien. H. C. and D. H. Wallace: Light induced leaflet orientation in Phaseolus viulgaris. Crop Sci. 18: 721-724 (1973).

Williams, P. M. and M. Sicardi-de-Mallorca: Effect of osmotically induced leaf moisture stress on nodulation and nitrogenase activity of Glycine max. Plant Soil 80: 267-283 (1984).
Williams. J. H.. R. C. N. Rao. R. Matthews, and D. Harris: Responses of groundnut genotypes to drought. In: Agrometeorology of Groundnut. (pp. 99-106). Sivakumar. M. V. K. and S. M. Virmani, Eds., ICRISAT, Patancheru. India (1986).

Williams, J. H. and N. P. Saxena: The use of non-destructive measurement of physiological models of yield determination to investigate factors determining differences in seed yield between genotypes of desi chickpeas. Ann. Appl. Biol. 119: 105-112 (1991).

Wilson, D.: Breeding for morphological and physiological traits. In: Plant Breeding II. (pp. 233-290), Frey. K. J.. Ed., lowa State University Press, Ames. IA (1981).

Winter. $\mathrm{K}$.: $\mathrm{CO}_{2}$ and water vapor exchange. malate content and ${ }^{13} \mathrm{C}$ value in Cicer arietenum grown under two water regimes. Z. Pflanzenphisiol. 101: $421-430$ (1981).

Worrall. U. S. and R. J. Roughley: The effect of moisture stress on infection of Trifolium subterraneum L. by T. trifolii Dang. J. Exp. Bot. 27: 12.33-1241 (1976).

Wright. N. L. and G. L. Jordan: Artificial selection for seedling drought tolerance in boer love grass (Eragrostis curvula). Crop Sci. 10: 99-102 (1970).

Wright. L. N.: Drought influence on germination and seedling emergence. In: Drought Injury and Resistance in Crops. (pp. 19-44). Larson, K. L. and J. D. Eastin, Eds.. Crop Science Society of America, Special Publication No. 2. Madison, WI (1971).

Wright, G. C., R. C. G. Smith. and J. R. McWilliam: Differences between two grain sorghum genotypes in adaptation to drought stress. III. Physiological responses. Aust. J. Agric. Res. 34: 637-65I (1983).

Wright, G. C., K. T. Hubick, and G. D. Farquhar: Discrimination in carbon isotopes of leaves correlates with water use efficiency of field 
grown peanut cultivars. Aust. J. Plant Physiol. 15: 815-825 (1988).

Wright, G. C., K. T. Hubick, and G. D. Farquhar: Physiological analysis of peanut cultivars response to timing and duration of drought stress. Aust. J. Agric: Res. 42: 453-470 (1991).

Wright, G. C., R. C. Nageswara Rao, and G. D. Farquhar: Water-use efficiency and carbon isotope discrimination in peanut under water deficit conditions. Crop Sci. 34(1):92-97 (1994).

Zhao, Y.. S. Kamisaka, and Y. Masuda: Quantitative relations between osmotic potential and epicotyl growth in Vigna radiata as affected hy osmotic stress and cotyledon excision. Physiol. Plant. 64: 431-4.37 (1985). 